\title{
LA ANTROPOLOGÍA CHILENA EN RAPA NUI: UNA RETROSPECTIVA
}

Chilean Anthropology in Rapa Nui: A Retrospective

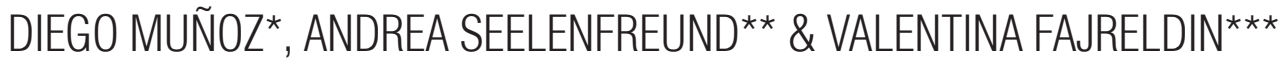

Fecha de recepción: 14 de septiembre de 2020 - Fecha de aprobación: 20 de septiembre de 2020

\section{Resumen}

El presente artículo analiza el desarrollo de la antropología -y en particular la antropología social chilena- en Rapa Nui y el lugar que ocupa la isla en la disciplina, al determinar sus características y aportes en la comunidad local. El estudio aborda tres dimensiones: 1) un análisis histórico de los paradigmas y las transformaciones teóricas en los estudios sobre Rapa Nui, 2) un abordaje de los estudios desde la institucionalización de la disciplina y 3) un análisis de las relaciones entre los investigadores y los informantes en la producción antropológica y sus repercusiones en la apropiación de los saberes por la comunidad isleña.

Palabras clave: Rapa Nui; Isla de Pascua; antropología chilena; perspectivas teóricas; antropología crítica.

\section{Abstract}

This essay analyzes the development of anthropology -and particularly Chilean social anthropology- in Rapa Nui and the place the island occupies in the discipline, determining its characteristics and contributions to the local community. In this essay we provide an analysis of three dimensions: 1) a historical analysis of the paradigms and theoretical transformations in Rapa Nui studies, 2) an approach the studies carried out since institutionalization of the discipline and 3) an analysis of the relationships between researchers and informants in the anthropological production and its effects on the appropriation of knowledge by the island community.

Keywords: Rapa Nui; Easter Island; chilean anthropology; theoretical perspectives; critical anthropology.

\footnotetext{
* Dr. en Antropología. Posdoctorante, Department of Social and Cultural Anthropology, Ludwig-Maximilian-Universität, Munich, Alemania. Correo-e: diego.munoz@ethnologie.Imu.de

** Dra. en Arqueología. Profesora titular, Escuela de Antropología, Facultad de Ciencias Sociales, Universidad Academia de Humanismo Cristiano, Santiago, Chile. Correo-e: aseelenfreund@academia.cl

*** Doctoranda en Antropología y Comunicación U. Rovira i Virgili. Profesor Asistente Facultad de Odontología, Universidad de Chile, Santiago, Chile. Correo-e: vfajreldin@odontologia.uchile.cl
} 


\section{Introducción}

El 17 de noviembre de 2018 desarrollamos en Rapa Nui' el seminario "Rapa Nui: patrimonio, sociedad y cultura desde una perspectiva contemporánea"2. Este reunió a investigadores y profesionales activos en el campo de la antropología, la historia y la gestión patrimonial de la isla. Con él quisimos dar continuidad a los congresos internacionales patrocinados por la Easter Island Foundation que culminaron con el congreso de Berlín en 2015. También quisimos crear la instancia para que profesionales y académicos pudieran reflexionar sobre temáticas y problemáticas expresamente excluidas del congreso "Early Pacific Migration", organizado por la Fundación Mata Ki te Rangi (MKTR) en los días previos y que son centrales en varios aspectos de la vida cotidiana. Nos pareció importante posicionar como legítima, pertinente y necesaria a la antropología social en el campo de los estudios rapanui por sobre los enfoques que por años han restringido la discusión e interés académico a la arqueología. Por último, pretendíamos poner en valor la producción antropológica en español (aunque contamos con ponencias en idioma inglés), la investigación interdisciplinaria y su carácter internacional, junto con presentar los trabajos a una audiencia tanto rapanui como internacional de académicos del Pacífico. Por ello, el simposio se realizó en la isla, abierto a la comunidad rapanui e inmediatamente posterior al congreso de la MKTR.

A partir de este contexto nos pareció necesario reflexionar sobre el desarrollo de la antropología -y en particular sobre la antropología chilena- relacionada con Rapa Nui. En este artículo proponemos abordar el desarrollo de la investigación antropológica desde la primera expedición científica chilena del siglo XIX hasta nuestros días, buscando responder a dos preguntas fundamentales: ¿Cuáles son las características y la trayectoria de la antropología chilena sobre Rapa Nui? ¿Ha seguido el mismo camino de la antropología chilena en general?

A partir de ello, este artículo tiene tres objetivos: 1) establecer los enfoques paradigmáticos usados en los estudios antropológicos sobre Rapa Nui, 2) dar cuenta del lugar de Rapa Nui en la antropología chilena y 3) reflexionar sobre las contribuciones a la comunidad local.

En la primera parte abordaremos desde una mirada histórica, los paradigmas y las transformaciones teóricas en los estudios sobre la isla; en la segunda, revisaremos el abordaje disciplinar desde lo institucional y, finalmente, analizaremos el rol de los rapanui en la producción de conocimiento antropológico.

\section{Retrospectiva: paradigmas y transformaciones}

Los intelectuales chilenos que han reflexionado sobre la trayectoria de la antropología chilena están de acuerdo en que la consolidación de la disciplina fue tardía. Su institucionalización universitaria comenzó después de 1960 y experimentó una importante ruptura durante la dictadura chilena (1973-1990) y un nuevo auge a partir los años noventa (Arnold, 1990; Palestini, Ramos \& Canales, 2010; Bengoa, 2014). Previo a su institucionalización, el conocimiento antropológico, esto es, el interés en la diversidad cultural y en las formas de vida de los pueblos indígenas del país, era desarrollado por investigadores extranjeros, radicados en Chile y que 
provenían de disciplinas tales como la historia y la geografía. En esta fase, que Palestini et al. (2010) denominan "pre-universitaria" y que Bengoa (2014) caracteriza por ser realizada por "sabios", la antropología se desarrollaba desde los museos o desde las sociedades científicas y tenía por principal interés la recolección de la cultura material de los pueblos indígenas tanto del pasado como del presente. Estos estudios seguían un modelo interpretativo que Bengoa (2014) Ilama "naturalista", en el cual el ser humano se encontraba incorporado al mundo natural y a la geografía, y que se apoyaba en el enfoque científico del evolucionismo. Desde esta perspectiva, el mundo indígena era leído como atrasado y en vías de desaparecer.

En una etapa posterior, pero aún desde una antropología pre-universitaria, el paradigma en vigor de los estudios antropológicos realizado en Chile tuvo por objetivo "rescatar los fragmentos de las culturas destinadas a desaparecer" (Bengoa, 2014, p. 17). Estas investigaciones que Bengoa (2014, p. 17) Ilama "rescatistas", fueron realizadas tanto por científicos de otras disciplinas como por misioneros jesuitas y capuchinos. En cuanto a Rapa Nui, como veremos, el rescatismo fue realizado tanto por exploradores como por antropólogos profesionales extranjeros.

El naturalismo y el rescatismo marcarán la pauta de los estudios antropológicos en esta primera fase de la antropología chilena. Cabe destacar que ni Palestini et al. (2010) ni Bengoa (2014) hacen referencia a los estudios sobre Rapa Nui. Estos parecen estar fuera de la trayectoria de la antropología chilena tanto en su etapa preuniversitaria como en su fase institucionalizada posterior.
Mostraremos a continuación que el desarrollo de la investigación de carácter antropológico sobre Rapa Nui se enmarca en una trayectoria similar a la descrita por dichos autores, pero presenta variaciones importantes que permiten pensar en una trayectoria paralela, tanto de los enfoques y paradigmas, como de los temas de interés. La exclusión de los estudios sobre Rapa Nui en el desarrollo de la antropología chilena tiene varias razones que se pueden resumir en el estatus ambivalente otorgado a los rapanui y su isla en el seno de la nación y el Estado chileno.

Desde el siglo XIX y cuando la élite ilustrada intentaba forjar la identidad nacional chilena, Rapa Nui no aparece mencionada más allá del hecho colonial de la anexión del territorio (9 de septiembre de 1888). Los discursos sobre la identidad chilena, sea en su variante mestiza o hispana (Larraín, 2001), no incluían a los rapanui ni como un componente de "la patria" ni como parte de los "otros internos", como lo fueron, por ejemplo, los mapuche. Si se considera que sus territorios históricos fueron incluidos a las fronteras nacionales en el mismo período de expansión colonial chilena, llama la atención que ambos pueblos fueron conceptualizados de manera diferente ${ }^{3}$. Mientras que los pueblos indígenas en Chile eran Ilamados "indios" y eran conceptualizados como un problema para el desarrollo de la nación (Larraín, 2001), los rapanui eran llamados canacas (Muñoz, 2017a), palabra de origen polinésica incorporada en el habla chilena (Lenz, 1905). En este contexto, los problemas existentes en la lejana isla, producto de una política colonial de abandono y explotación ganadera por agentes privados, no eran vistos como un asunto nacional, sino bien avanzado el siglo XX cuando se levanta la demanda por "chilenizar Rapa Nui" (Foerster \& Montecino, 2018). 
De este modo, los rapanui, desde el inicio de la presencia chilena, fueron considerados como un otro externo y, por lo tanto, excluidos de la sociedad nacional. A partir de los años sesenta se observa un cambio de perspectiva que se acentúa con la integración del territorio insular a la administración civil del país y que gatilló un marcado proceso de chilenización $n^{4}$.

Teniendo en consideración el lugar ambiguo que ocuparon los rapanui y su isla en la construcción nacional, los primeros estudios antropológicos realizados $u$ organizados desde Chile tuvieron como objetivo registrar y describir los vestigios materiales de la sociedad del pasado para incorporarlos al patrimonio nacional, ignorando la presencia de los rapanui como actores relevantes.

El interés por el rescate de los vestigios de una cultura considerada en vías de desaparecer fue la segunda gran preocupación. A diferencia del impulso nacional de apropiación patrimonial, este interés provino del extranjero. Las principales investigaciones fueron realizadas desde un comienzo por antropólogos profesionales, a los que se sumaron algunos misioneros que residieron en Rapa Nui durante varios meses e incluso años, quienes se mostraron sensibles a las condiciones de vida de los isleños.

Así, durante toda la primera mitad del siglo $X X$, la mayoría de la información de interés antropológico sobre Rapa Nui que circulaba en Chile tenía su origen no en investigaciones antropológicas sistemáticas o enmarcadas dentro de programas de investigación, sino como informes oficiales o reportajes de prensa redactados por unos pocos visitantes (i.e. Foerster, 2015 y Foerster \& Montecino, 2018). Esto puede explicar también por qué Rapa Nui nunca fue observada desde el indigenismo, principal paradigma de la naciente antropología académica chilena de las décadas de 1940 y 1950.

Con la institucionalización de la antropología chilena, a través del Centro de Estudios Antropológicos (CEA) en los años cincuenta, parte de sus miembros pasan a actuar como contraparte chilena de las misiones científicas extranjeras desarrolladas en Rapa Nui. El énfasis en la investigación en ese entonces estuvo en el registro y la puesta en valor del patrimonio arqueológico por medio de la restauración de sitios monumentales y el inicio del programa de prospección arqueológica, ambos financiados por fondos internacionales y nacionales ${ }^{5}$. Recién a partir de los años setenta podemos observar el desarrollo de investigaciones antropológicas, que pondrán de relieve lo que llamaremos el presente etnográfico.

A continuación revisaremos el desarrollo de los estudios antropológicos sobre Rapa Nui distinguiendo aquello relacionado con la trayectoria general de la antropología chilena de lo que se presenta como particular a los estudios sobre la isla e identificando paradigmas y tendencias temáticas.

\section{La mirada naturalista}

Durante el siglo XIX varios intelectuales chilenos abogaron porque la investigación científica fuese un emblema identitario de un país moderno y progresista. Como parte de este esfuerzo, Rudolf A. Phillipi, director del Museo Nacional, promovió la creación de una colección que presentara "lo chileno" y "lo exótico" del territorio nacional. En los museos de historia natural, 
que en su concepción fueron una continuidad de los gabinetes de curiosidades surgidos en el siglo XVII y XVIII en Europa, todos los objetos provenientes de sociedades no occidentales eran conceptualizados como parte de la "historia natural". Las sociedades científicas chilenas del siglo XIX y principios del siglo XX, siguiendo el modelo francés, definieron la ciencia antropológica como "historia natural del hombre" (Porter, 1909; Lenz, 1924). Esta estaba constituida por: la antropología (descripción anatómica, física y patológica), la etnografía (descripción de tribus o naciones aisladas), la etnología, la lingüística, la arqueología y la prehistoria (Porter, 1909). Así, el museo de "ciencias naturales" contenía elementos de la naturaleza, pero también de las poblaciones indígenas, bajo una denominación de antigüedades, en la que los límites entre los objetos arqueológicos y los etnográficos estaban poco claros (Schell, 2001). Cabe destacar que hasta principios del siglo $X X$ no existía una sección de antropología en el museo, a pesar de contar con una colección de 1.086 objetos etnográficos y sobre 3.687 piezas arqueológicas (Moore, 1910). Esta sección recién se crea en 1914 (Mora, 2016).

Phillipi organizó diversas expediciones tanto al norte como al sur de Chile y encargó también a otros las observaciones, los registros y la colecta de objetos con la finalidad de acrecentar las colecciones del museo. Uno de estos encargos los recibió el capitán de marina Ignacio Gana, comandante de la nave O'Higgins, para observar y registrar la historia natural de Isla de Pascua en el año 1870, dieciocho años antes que el Estado chileno la incorporara a su territorio. Se trata de la primera expedición chilena a la isla. La misión, aparte de ser una excursión de formación de cadetes e infantes de marina, era recopilar toda la información necesaria para determinar si el territorio podía y ameritaba ser anexado por el país (Phillipi, 1874).

La misión de la O'Higgins tuvo mucho en común con las expediciones europeas del siglo XVIII en el Pacífico, caracterizadas por una mezcla de intereses expansionistas y científicos, lo que da cuenta de un fenómeno epocal para observar las relaciones dentro de una lógica colonial mayor. Los informes redactados por los capitanes y el médico de a bordo son las primeras informaciones de interés etnográfico producidas desde Chile, mientras que los objetos recolectados pasaron a formar parte de la colección del Museo de Historia Natural.

Destaquemos que la información colectada fue utilizada por Philippi, junto a algunos de los diarios de los navegantes europeos ${ }^{6}$, para redactar su Jeografía de la Isla de Pascua y sus habitantes (1874), texto que se inscribe en lo que Bengoa (2014) llama una mirada naturalista. Phillipi describe la geografía, el clima, la flora, la fauna y los habitantes, centrándose en su físico, en elementos de la "religión" y "los usos y costumbres". Los habitantes eran parte de la geografía del lugar. Incluye además una descripción sobre "las estatuas y esculturas de piedra y madera". Su texto termina con la descripción de los objetos recolectados por la misión de $1870^{7}$ y aporta un vocabulario, extraído de los informes redactados por los oficiales de la O'Higgins.

Este texto resume las interrogantes que guiarán durante los siguientes cincuenta años las investigaciones, centradas en el estudio de las construcciones megalíticas, en el origen de los habitantes y en el desciframiento de los rongorongo como eventual sistema de escritura. Al mismo tiempo, la población fue conside- 
rada en vías de desaparición, tanto por razones demográficas, sanitarias como culturales ${ }^{8}$. Este texto llegó a ser una importante fuente para los estudios antropológicos de la primera parte del siglo XX, siendo una de las escasas referencias de origen chileno para el estudio de Rapa Nui. Otras descripciones del período rescatan aspectos tales como la nutrición, que se catalogó de pobre por no incluir proteínas animales, o el clima húmedo, a la par de las conductas sexuales, leídas con patrones morales de la época y elementos de juicio a la hora de calificar el estado degradado de sus habitantes. Claros fueron los conceptos emanados de un imaginario en torno de la otredad de un sujeto exótico al que era posible atribuirle un canibalismo gastronómico producto de un estado de guerra permanente (Polakowsky, 1895; Ossandón, 1903) ${ }^{9}$. El enfoque naturalista se mantiene presente incluso en algunos trabajos de mediados del siglo XX (Bórmida, 1951).

La segunda expedición organizada desde Chile que recogió datos antropológicos fue la misión meteorológica de 1911 de la Universidad de Concepción, dirigida por el ingeniero alemán con residencia en el país, Walter Knoche. Esta misión se inscribe en la misma lógica de aprehensión de Rapa Nui como objeto científico desde las ciencias naturales. Knoche, acompañado por el botánico del Museo Nacional de Historia Natural, Francisco Fuentes y su ayudante Edgardo Martínez, tenía como objetivo instalar una estación meteorológica, otra sismológica y estudiar desde el higienismo la situación sanitaria de los habitantes, en especial de los leprosos (Knoche, 1912a, 1913). Solo por interés personal, Knoche registró un importante corpus de información etnográfica (Mückler, 2015). Con él empezamos a reconocer la emergencia de un nuevo paradigma para leer
Rapa Nui, consistente en la recopilación de leyendas y la descripción de prácticas sociales vistas como vestigios. Knoche se interesó en el tatuaje, que califica como una práctica extinta, en la recopilación de leyendas para salvaguardarlas (Knoche, 1912b) y en la colecta de objetos etnográficos (Knoche, 1926, 1927). Edgardo Martínez, quien permaneció en la isla durante un año, se interesó en la lengua y publicó el primer vocabulario bilingüe producido en Chile ${ }^{10}$ (Martínez, 1913).

El interés científico de carácter naturalista por parte del Estado de Chile fue intermitente y circunstancial: si en 1870 primaba el interés por una expansión territorial de Chile hacia el Pacífico y para tales efectos se relevó información tanto geográfica, demográfica como sanitaria, en 1911 -ya anexada la isla a Chile- se estudiaban los potenciales económicos del suelo isleño. Después de estas dos expediciones no vemos un nuevo esfuerzo en el estudio de este territorio por parte del Estado sino hasta 1935, cuando se releva su valor patrimonial. Sin embargo, no será hasta los años sesentas en que la investigación antropológica y sobre todo la arqueológica, adquieren una mayor relevancia desde Chile (Seelenfreund, 2009).

\section{La mirada rescatista y el giro etnológico}

El enfoque del rescate es la continuidad lógica de la mirada naturalista en el sentido de recopilar, clasificar y describir la totalidad de una realidad dada. En el caso de Rapa Nui, sus habitantes eran vistos como vestigios vivientes de un pasado glorioso y misterioso, próximos a desaparecer (Phillipi, 1874; Routledge, 1919; Métraux, 1971 [1941]; Barthel, 1978), de ahí la importancia y 
la urgencia de salvaguardar cuanta información fuese posible sobre los modos de vida tradicionales. En esta lógica, el patrimonio arqueológico, que a los ojos de la época era el vestigio de una alta civilización de la antigüedad, se consideraba distanciado de la población rapanui observada. El obispo Edwards (1918), quien había visitado la isla en dos ocasiones (1916 y 1917), y que representaba una de las altas autoridades morales de Chile, escribe respecto de Rapa Nui y sus vestigios:

¿Quiénes fueron los primeros pobladores de esta isla? ¿de dónde vinieron y cómo llegaron hasta ella? Hubo en una época remota en la Isla de Pascua una población numerosa y de un alto grado de cultura. Para afirmarlo basta contemplar los restos, desafiando el tiempo y a la codiciosa barbarie de los hombres, aún quedan de las obras que llevaron a cabo los primeros pobladores. En las orillas del mar y en las laderas de los volcanes se contemplan hasta hoy los restos de construcciones gigantescas. Los dilatados malecones, los cimientos de los palacios, tal vez antiguos templos, que eran justamente antiguos cementerios, son mudos testigos de sacaremotas [sic] grandezas... ¿qué pueblo, qué raza realizó estas obras? las tabletas y piedras con inscripciones jeroglíficas [...] son indicios de la cultura de los antiguos pobladores de Pascua. Sólo en los pueblos más adelantados se encuentran vestigios de escritura [...] centenares de estatuas se ven diseminadas por la Isla, de pie algunas, caídas las más: quiénes fueron los soberbios faraones que levantaron estos monumentos? ¿Cuál es su significación? ¿Quién y con qué poderosos medios los arrastró a través de las praderas pedregosas y por las pendientes de los volcanes?. (pp. 7-9)

Hasta entrada la segunda mitad del siglo XX, el grueso de las investigaciones sobre Rapa Nui fueron realizadas por investigadores profesionales extranjeros y combinaban arqueología, estudios raciales y lo que hemos llamado el rescate de leyendas, historia y formas de vida entendidas como tradicionales (Barthel, 1978; Seelenfreund, 2007; Foerster, 2016; Muñoz, 2017a), las que eran relatadas por unos pocos informantes clave. Todos los investigadores señalaron en su momento que se encontraban frente a la dificultad del olvido de la cultura ancestral. Este enfoque y la necesidad del rescate pueden resumirse en el célebre comentario de Alfred Métraux (1957) cuando describe las "angustiosas" condiciones para el trabajo etnográfico que presentaba la isla. Para Métraux, no existía otra isla en todo el Pacífico en la que quedaran tan escasos vestigios de la cultura antigua (Métraux, 1971 [1941]).

La investigación sobre Rapa Nui en este período se inscribe en una serie de interrogantes mayores sobre la antropología y la arqueología del Pacífico que poco interesaba a la academia chilena o al Estado, visto que no se promovieron este tipo de estudios. Una de las grandes áreas de investigación era sobre los orígenes de los polinesios. Esta pregunta se plantea ya durante las primeras exploraciones europeas en la Oceanía del siglo XVIII (Howard, 1967). En el siglo XX, con posterioridad a la creación de museos antropológicos en Hawaii y Nueva Zelandia, se dio inicio a la antropología histórica del Pacífico y desde 1920 en adelante, la arqueología de esta región se ha preocupado por rastrear y establecer una "secuencia cronológica de dispersión y poblamiento" de las islas y los archipiélagos (Kirch, 2010). En esta época, instituciones como el Bishop Museum de Hawaii promovieron expediciones antropológicas y etnográficas que enviaron simultáneamente equipos de investigación a las islas Marquesas, a Tonga, a las islas Australes y a Hawaii. Cada equipo llevaba un etnógrafo para estudiar la organización social y religiosa y un arqueólogo para el estudio de la cultura material, en especial los monumentos de piedra, y "resolver el tema del origen de los 
polinesios" (Gregory, 1921). La expedición de Katherine S. Routledge a Rapa Nui, que si bien no fue promovida por una institución sino que contó con financiamiento privado, se enmarca bajo las mismas interrogantes.

Varios de estos estudios concluyen que desde la arqueología eran pocos los datos que se podían obtener en vista de la ausencia de depósitos estratigráficos. Bajo el prisma de las teorías difusionistas de la época, se promueven entonces los estudios antropológicos sobre migraciones, los que propusieron encontrar los orígenes de los polinesios en las culturas brahmánicas de la India o de Indo China (véase Handy, 1930 o McMillan-Brown, 1997 [1924] para Rapa Nui). Al mismo tiempo, entre 1920 y 1930, los antropólogos físicos proponen tabulaciones antropométricas y divisiones raciales de los pueblos oceánicos. Uno de los textos surgidos en esos años es la síntesis de Peter Buck (1938), forjada en un caldero de prejuicios raciales de principios del siglo XX (Saura, 2019).

El debate sobre los orígenes polinesios se trasladó rápidamente a los estudios en Rapa Nui, buscando todo tipo de relaciones con otras islas de Oceanía o incluso con Asia, por medio de paralelos en las construcciones megalíticas o bien a través de los estudios raciales. En estos estudios prima una atemporalidad en la cual la construcción de los monumentos, los restos arqueológicos de asentamientos, artefactos y datos etnográficos eran estudiados como objetos sincrónicos. La visión de una sociedad pasada inmutable, en ese entonces desaparecida, sienta las bases del ideario sobre los "misterios" de Rapa Nui y sus nexos con una "civilización perdida", ideas que han permeado la literatura popular sobre la isla.
La mirada rescatista tuvo la particularidad de otorgar un nuevo protagonismo a los rapanui, vistos ahora como informantes del pasado. Llamaremos a este cambio de enfoque el giro etnológico, el cual se produce principalmente con las investigaciones de Katherine Routledge y Alfred Métraux. El giro etnológico permitió salir del paradigma naturalista, que mostraba poco interés en los rapanui contemporáneos más allá de la hipótesis de su próxima extinción como "raza". Por otra parte, este enfoque permitió centrar la atención en recopilar información desde la memoria oral de los habitantes, la cual comenzó a ser vista como la mejor fuente para acceder al pasado, debido a la supuesta ausencia de depósitos estratigráficos (Lavachery, 1939). Los problemas a resolver seguían siendo los mismos: el origen de los habitantes, el significado, los modos de construcción y el transporte de los moai y el desciframiento del rongorongo.

Routledge, en sus casi 17 meses de estadía en Rapa Nui11, reconoció la importancia de lo que ella llamó "la memoria viva" conservada por los ancianos. Esto la llevó a recopilar una inmensa cantidad de información memorial, ayudada por un grupo de ancianos mujeres y hombres que habían nacido antes de la llegada de los misioneros, pero mucho después del paso de las primeras exploraciones europeas ${ }^{12}$. Con ellos pudo sacar a la luz ciertos elementos de la organización social, conceptos religiosos, rituales de iniciación, canciones, mitos e historia local, todos los cuales podían servir para reconstruir una imagen global de la sociedad del pasado ${ }^{13}$. Con Routledge y estos ancianos nace en Rapa Nui el oficio de informante, al mismo tiempo que algunos rapanui dan una nueva valorización a su pasado como fuente de interés para los extranjeros ${ }^{14}$. 
El principal intérprete de Routledge fue Juan Tepano, de unos 40 años de edad y que había estado en Chile, por lo que manejaba bien el castellano y tenía ciertas nociones de inglés. Tepano tradujo e interpretó toda la información dada por este grupo de ancianos, entre los cuales se encontraba su madre, Paulina Veriamo, nacida hacia 1830. Tepano será más tarde el principal informante de Métraux, quien lo califica de "maorit5 del folclore de la isla" (Métraux, 1971 [1941], p. 1) e indica además, que "su reputación llegaba hasta Chile" (Métraux, 1957, p. 23).

Si bien Routledge (1919) no publicó una obra científica sino más bien un libro sobre su viaje, este entregó un nuevo impulso a la posibilidad de entender el pasado rapanui desde los recuerdos de los habitantes vivos. Este impulso fue llevado casi al límite 15 años más tarde por Métraux, quien llegó a la isla a la cabeza de una misión científica europea.

A diferencia de la misión de Routledge, financiada con fondos privados (Van Tilburg, 2003), la llamada misión francobelga estaba auspiciada por el Instituto de Etnología de la Universidad de París, el Museo de Historia Natural de París, bajo la supervisión de Paul Rivet y del Museo Real de Arte e Historia de Bélgica. La expedición estaba compuesta por el ya mencionado Alfred Métraux ${ }^{16}$ como etnólogo y por Henri Lavachery como arqueólogo. El gobierno chileno instruyó la participación del médico Israel Drapkin con el objetivo de estudiar la situación de la lepra (Métraux, 1971 [1941]). Drapkin fue una incorporación de último momento para reemplazar a Charles Louis Watelin, quien falleció en la travesía del Cabo de Hornos (Lavachery, 1939). El objetivo último de la expedición era dar respuesta al "misterio" de la escritura rongorongo, de la cual se especulaba tenía un origen en el valle del Indo en Pakistán (Laurière, 2014) ${ }^{17}$.

En solo seis meses de trabajo de campo, Métraux, junto a unos pocos hombres y mujeres, todos nacidos durante la segunda mitad del siglo XIX y en los albores del XX, y con un importante trabajo posterior de comparación etnológica, logró resituar a Rapa Nui dentro de la literatura antropológica del Pacífico. Reconoce haber llegado muy tarde pues lamenta que varios ancianos habían muerto en 1927 debido a una epidemia de tuberculosis, y que las personas ancianas tenían ya una memoria frágil (Métraux, 1971 [1941]). A pesar de ello, su obra es aún hoy el trabajo etnológico más completo sobre el pasado de Rapa Nui que continúa alimentando la reflexión antropológica y arqueológica. Métraux intenta dar por terminada la interrogante sobre los orígenes de los habitantes y da una interpretación convincente del rongorongo como un sistema mnemotécnico (Métraux, 1971 [1941]; Fischer, 1997). En cuanto a los trabajos arqueológicos, estos estuvieron a cargo de Lavachery, que en gran medida dedicó su tiempo a prospectar la costa norte y registrar los petroglifos. Sus escritos sobre el arte rupestre, en particular los petroglifos, siguen vigentes (Lavachery, 1939). Por su lado, Drapkin (1935) no solo se dedicó al estudio de la lepra, sino que hizo los primeros estudios demográficos y de grupos sanguíneos, además de contribuir a la expedición con la colecta de flora y fauna para alimentar las colecciones de "historia natural" de los respectivos museos europeos (Métraux, 1971 [1941]).

El hecho que el volumen Ethnology of Easter Island de Métraux fuese publicado por el Bishop Museum de Hawaii y apoyado por Peter Buck, 
en ese entonces su director; que la misión haya sido organizada desde París y Bruselas y ejecutada por un investigador suizo, otro belga y un chileno incorporado en último momento, demuestra que hasta ese momento Rapa Nui era foco de interés de una antropología internacional, vinculada además a importantes centros de investigación en el Pacífico y Europa. Esta tendencia continuará, al menos para los estudios arqueológicos, hasta la actualidad.

El impacto de la misión francobelga se dejó sentir en Chile en dos ámbitos. En primer lugar, por la valorización de la isla como lugar patrimonial. En efecto, cuando la misión dejó Rapa Nui en enero de 1935, transportó a Europa un moai, una cabeza de moai y varios objetos arqueológicos y restos humanos. En ese momento, el gobierno chileno tomó conciencia que la isla podía ser un lugar de interés patrimonial. En el imaginario nacional, la monumentalidad de los restos arqueológicos le daba al país un lugar en la lista de las grandes civilizaciones de la antigüedad, comparable a los antiguos egipcios y sumerios, como ya lo había sugerido el obispo Edwards. Esta interpretación contribuyó a crear un "orgullo nacionalista" en la apropiación de Rapa Nui como patrimonio nacional (Faba, 2012). En este contexto, la salida de restos arqueológicos fue conceptualizada como un expolio del patrimonio del país, aunque dichos vestigios no estaban aún protegidos legalmente (Ministerio de Relaciones Exteriores, 1935). En segundo lugar, por la obtención de 35 piezas etnográficas africanas que llegan al Museo Nacional de Historia Natural procedente de las colonias francesas. Aunque Latcham (1936) lo describe como una "retribución" por el apoyo que recibió la expedición francobelga, se trató en realidad de una compensación negociada por el Museo Etnográfico de París por la salida no autorizada de Chile de los objetos (Ministerio de Relaciones Exteriores, 1935).

Esta situación llevó a la elaboración de una misión científica chilena destinada principalmente a levantar un inventario de los restos arqueológicos para su futura puesta en valor (Vergara, 1939), lo cual fue materializado en 1935 con la inscripción de Rapa Nui como Parque Nacional18 y Monumento Histórico ${ }^{19}$. Se trata entonces de la tercera misión chilena. Curiosamente, la persona encargada del estudio fue el misionero capuchino Sebastián Englert, quien se convertirá en otra de las fuentes imprescindibles para aproximarse a la historia rapanui.

El trabajo de Englert es de una complejidad mayor y complementa los resultados de Métraux. Englert fue más sensible a lo que podemos denominar la historia local cuando posiciona a sus informantes en largas genealogías. Como lo ha indicado Muñoz (2017b), Englert logró conectar con personas vivas a varios de los personajes que aparecían en las leyendas recopiladas. La memoria genealógica, si bien reconocida ya por Routledge como importante, es con Englert que adquiere toda su relevancia para la reconstrucción histórica y las cronologías arqueológicas. Otra de sus contribuciones fue el publicar en español y en rapanui una serie de leyendas, una gramática y un diccionario de la lengua, haciendo accesible dicho material en Chile (Englert, 2006 [1936]). Cabe destacar que su libro de difusión, La tierra de Hotu Matu'a (1948), contribuyó a establecer una versión canónica del mito de poblamiento tanto para los futuros investigadores como para la comunidad rapanui (Muñoz, 2017a).

Los trabajos etnológicos realizados por misioneros se inscriben dentro de la misma lógica 
del rescate enunciada por Bengoa (2014), pero que en el caso de Rapa Nui tuvieron la particularidad de abordar también la historia moderna. Notables son los registros dejados por el también capuchino padre Bienvenido de Estella $(1920,1921)$, que plasmaron cómo los rapanui recordaban e interpretaban la anexión, cómo vivían el catolicismo, así como también cómo festejaban los nacimientos o sufrían las muertes. Esta etnografía misionera fue sensible al momento presente, lo que paradójicamente aparece descuidado tanto por Métraux como por Englert.

El paradigma rescatista encontró un nuevo impulso en 1955 cuando, durante la expedición noruega organizada por Thor Heyerdahl ${ }^{20}$, se toma conocimiento que algunas familias conservaban antiguos cuadernos donde habían transcrito leyendas. Dos años más tarde, el etnólogo alemán Thomas Barthel centrará su investigación en descifrar uno de estos textos: el "Manuscrito E".

La visita de Barthel en 1957 se realizó durante su estadía en el recientemente formado Centro de Estudios Antropológicos de la Universidad de Chile (CEA). Como resalta el autor, su intención no era el rescate de conocimientos antiguos. En una carta dirigida a Métraux relata:

[...] voy a hacer un estudio de los cambios culturales más destacados que tuvieron lugar desde vuestra estancia en 1934-35. Como en breve se completará la nueva pista de aterrizaje, parece necesario hacer esta investigación. Este "re-estudio" puede resultar de mayor interés científico que hurgar por tradiciones antiguas $^{21}$. (en Fischer, 2009, p. 5)

Sin embargo, contrario a sus expectativas, como algunas familias rapanui mantenían un interés activo en los conocimientos de su pasado, su trabajo de campo terminó centrándose en discusiones sobre una "cultura de memoria" (memory culture) (Barthel, 1978, p. ix). La nueva posición del rapanui como informante del pasado le permitió a Barthel interpretar desde el interior el "Manuscrito E", documento que narraba en detalle el descubrimiento de la isla, la preparación y la migración de Hotu Matu'a, Ava Rei Pua y Tu'u Ko Iho, así como los pormenores de la colonización (Barthel, 1978).

Barthel a diferencia de Métraux, que solo nombra a dos de sus informantes (Juan Tepano y Victoria Rapahango), entrega la identidad de cada uno de ellos, lo que permite hoy saber cuáles eran las familias rapanui que detentaban un saber memorial. Al mismo tiempo, su trabajo de interpretación se alimentó de los resultados de investigación de Métraux y Englert, con quienes mantuvo un estrecho contacto (Fischer, 2009). El trabajo de Barthel, si bien sigue la pauta de una etnografía rescatista, fue pionero por su mirada comparativa, al posicionar e interpretar los relatos del Manuscrito $E$ en el contexto de la cosmología polinésica y de comparación lingüística.

En esta misma línea de trabajo comparativo encontramos la investigación de Horst Cain y Anette Bierbach sobre religión y etnolingüística. Ambos investigadores alemanes, con una amplia trayectoria de investigaciones en Samoa (Cain, 1979), realizaron un estudio sobre "la terminología mágico-religiosa de Rapanui" (Bierbach \& Cain, 1996, p. vii). Al igual que Barthel, lograron posicionar la antigua cosmovisión rapanui en el contexto polinesio, dado los escasos estudios realizados sobre estos aspectos de la cultura insular. 
Si bien hasta ahora todas estas investigaciones se centraron en una información memorial bajo la forma de leyendas, técnicas y genealogías, que permitían interpretar los vestigios arqueológicos, una nueva área de interés aparece con el trabajo del médico residente durante la década de 1970, el chileno Ramón Campbell, la cual permitía otro acceso al pasado. Se trata de la etnomusicología. Campbell, a justa razón, indica que estos estudios habían sido descuidados por Routledge, Métraux e incluso por Englert. Campbell (1971) propuso una tipología y una clasificación cronológica de los cantos en la que consideró dos grandes momentos: una etapa de "Música Antigua", desde tiempos remotos hasta 1917, en contraste con la "Música Moderna" (desde 1917 hasta la actualidad).

Asimismo, en su calidad de médico, Campbell registró varias prácticas y saberes médicos, que incluyen una copiosa terminología en lengua rapanui sobre ciclos vitales, cuerpo, sexualidad, embarazo, parto, puerperio, entre otros, que registran tanto lo observado por él como lo obtenido de sus informantes y que portan una alusión vaga a un pasado remoto (Campbell, 1993).

Todas estas investigaciones que proponían rescatar los vestigios de la cultura rapanui, desde Routledge hasta Campbell, poseen un problema de fondo en la interpretación etnológica importante de resaltar. Si bien todas tenían por objetivo reconstruir lo más fielmente posible la sociedad rapanui del pasado, dicho pasado se presenta "fuera del tiempo" (Thomas, 1996). Todos tenían el objetivo de entender la sociedad del tiempo en que los moai estaban aún de pie a través de los recuerdos de los ancianos. Sin embargo, ninguna de las personas que oficiaron como informantes vivieron en dichos tiempos. Es más, todos los informantes de Routledge habían nacido al menos cien años después de las primeras visitas europeas. Con los informantes de Métraux, Englert, Barthel y Campbell el dilema se acrecienta, puesto que la mayoría había nacido a finales del siglo XIX. El pasado de esta sociedad aparece así indeterminado, se distancia sustantivamente de lo que los autores observan en sus pares temporales. Por otra parte, los recuerdos secundarios, más que enunciar un pasado histórico lejano, eran más bien interpretaciones locales del pasado, muchas veces reciente. Ambos dilemas es lo que Fabian (2002) llamó la negación de la co-temporalidad. La información memorial recopilada estaba haciendo referencia a una sociedad profundamente transformada y no a aquella en la cual los rapanui no conocían influencias externas a su sociedad. Por otra parte, como hemos indicado más arriba, el momento presente, a excepción de Routledge y la etnografía misionera, fue profundamente descuidado.

\section{La mirada de la aculturación}

A partir de 1960 la antropología chilena entra en su fase de institucionalización (Arnold, 1990; Palestini et al., 2010; Bengoa, 2014). Veinte años después de la formación del Centro de Estudios Antropológicos de la Universidad de Chile (CEA), vemos a un primer equipo de investigadores chilenos interesados en Rapa Nui. Las hipótesis de principios de siglo, que anunciaban la desaparición de esta sociedad y de la "raza", dejaron de concentrar los esfuerzos interpretativos dando paso al estudio de la aculturación. Este cambio de paradigma de la antropología chilena fue influenciado por la antropología 
norteamericana, donde el método prestaba atención a los contactos culturales y los efectos de estos en el cambio cultural. La cultura era conceptualizada como un conjunto de saberes, prácticas y valores propios y autónomos de cada grupo humano y se entendía a los sujetos como portadores de la misma; de modo que el contacto cultural implicaba la transformación del sistema nativo, influenciado por la cultura foránea (Linton, 1945) ${ }^{22}$.

Los análisis sobre la aculturación se inician durante la expedición noruega y provienen de los escritos del arqueólogo norteamericano Edwin Ferdon (1957, 1958). Sus textos, aunque poco citados en el medio antropológico chileno, fueron pioneros por el interés dado al presente etnográfico y marcaron una importante diferencia respecto del trabajo de Métraux y de Barthel. Recordemos que Métraux (1971 [1941]) expresó que su misión etnológica de 1934 descuidó el análisis de la aculturación que era lo "verdaderamente interesante" en la isla. En opinión de Ferdon:

Hoy en día, el contacto inicial con los nativos de la Isla de Pascua y su pueblo de Hangaroa crea la ilusión definitiva de que aquí la aculturación hacia un patrón chileno se acerca a su finalización y es solo cuestión de que el gobierno apruebe las leyes necesarias para darles el derecho al voto hasta que se produzca la absorción final que está en buen camino. Rasgos tales como casas en marcado estilo europeo o casas con paredes de cemento con techos de hojalata ondulada, la plena aceptación de la cabalgata y de la cultura del caballo, el uso ocasional de carretas y arados tirados por bueyes y la completa aceptación de las vestimentas europeas, incluyendo zapatos bien lustrados el día domingo, reflejan más bien un entorno continental rural que una isla habitada por polinesios en el Pacífico. $(1957, \text { p. } 224)^{23}$
El enfoque de la aculturación se vio perennizado en la antropología chilena sobre Rapa Nui con el trabajo realizado por el recientemente formado Instituto de Estudios de Isla de Pascua de la Universidad de Chile ${ }^{24}$. En agosto de 1981 se realizó en la isla el Primer Seminario de Antropología de Isla de Pascua, en el que el equipo encabezado por Claudio Cristino, presentó los primeros resultados de una investigación realizada in situ desde 1979. Esta investigación pretendía identificar cómo la cultura rapanui había cambiado a lo largo de su historia. De esta presentación, emana un documento que marcará el tono de la reflexión antropológica chilena sobre Rapa Nui (Cristino, Recasens, Vargas, González \& Edward, 1984). Su título resume el propósito: "Isla de Pascua: Procesos, alcances y efectos de la aculturación". Tomando como referencia el trabajo de Ferdon y de los teóricos norteamericanos de la aculturación, como Herskovitz, Linton y Redfield, el equipo propone la siguiente tesis (Cristino et al., 1984):

Desde su descubrimiento en 1722, la Isla ha sido escenario de un continuo y progresivo proceso de aculturación. Este presenta una secuencia abigarrada de cambios sociales y culturales, cuyas características dependen en parte del tipo de agentes que intervinieron, de cuáles fueron sus motivaciones y de la intensidad de su acción sobre la población. Este fenómeno ha venido a ser problematizado en la actualidad, a raíz de haberse iniciado en las dos últimas décadas una acelerada y multifacética aculturación, debido a la introducción en la Isla de una serie de cambios de carácter económico, social, cultural y político. (p. 6)

El objetivo de este enfoque era:

[...] determinar exactamente qué es esta "cultura pascuense", cuáles han sido sus respuestas frente a los contactos diferenciales que ha sufrido, qué cambios sustanciales han producido éstos y, cuáles son, desde esta perspectiva, los actuales problemas de la población. (Cristino et al., 1984, p. 1) 
Bajo este prisma teórico, el equipo chileno leyó la historia rapanui identificando las mutaciones ocurridas tanto en la organización social como en el sistema de creencias. El impacto de la publicación de Cristino et al. (1984) se debió principalmente al hecho que fue una de las primeras en sistematizar la historia contemporánea de la sociedad, pero por sobre todo, porque fue durante años el único trabajo publicado en castellano y por tanto, accesible para las nuevas generaciones de estudiantes de antropología.

Los autores proponen una periodización de los "contactos culturales" que generaron "cambios en los patrones culturales". Esta, como lo ha señalado recientemente Foerster (2016), sigue siendo de utilidad. En su periodización, la última fase es llamada "sociedad abierta", que, según Cristino et al. (1984), se caracteriza por:

[...] la apertura total del sistema. La Isla se vincula estrechamente con el mundo exterior a través de los medios de comunicación, contactos aéreos permanentes y la llegada de grandes contingentes de funcionarios continentales, extranjeros y turistas, que generan profundos cambios del modo de vida isleño. El isleño busca la "continentalización" y adhiere a todas las formas externas de la cultura occidental, modificando día a día su modo de vida "tradicional". (p. 29)

La conceptualización de esta fase dio el marco a la emergencia de nuevas temáticas de investigación que si bien no fueron numerosas, permitieron salir del enfoque rescatista y concentrarse en el presente etnográfico. Así por ejemplo, en los años ochenta aparecen los primeros trabajos sobre la emigración rapanui a Chile continental (Goñi, 1983; Santibañez, 1986), fuertemente influidos por la teoría de la aculturación que se aplicaba a otros contextos chilenos desde los años cincuenta (Munizaga, 1961).
Resulta interesante constatar que al mismo tiempo en que los antropólogos chilenos leen los cambios en la sociedad en términos de aculturación, investigadores extranjeros empezaban a leer la historia rapanui como una serie de adaptaciones y modos de resistencia o reapropiación, donde una matriz cultural propia modificaba los elementos foráneos (McCall, 1976; Porteous, 1981; Delsing, 2009). Se empieza así a conceptualizar y observar los procesos que podemos llamar de "resiliencia", tanto en el pasado como en el presente.

\section{La mirada de la resiliencia}

El concepto de resiliencia hace referencia a la capacidad de los individuos de sobreponerse a una situación traumática; es un concepto venido de la psicología social utilizado en antropología por Gregory Bateson (1972). Este enfoque fue el aplicado por Grant McCall en su tesis de doctorado titulada Reaction to Disaster: Continuity and Change in Rapanui Social Organisation (McCall, 1976). Su hipótesis es que los rapanui tuvieron la capacidad de "reaccionar al desastre", como lo indica el título de su trabajo. En esta "reacción", McCall identifica que ciertos aspectos de la cultura profunda sirvieron para modificar y adaptar las influencias foráneas a la cultura local. El autor discute las tesis de Ferdon para poner en evidencia cómo una matriz cultural rapanui actuaba en un proceso de adaptación, reapropiación y rechazo de las influencias externas.

El libro que McCall pública después de su tesis doctoral, titulado Rapanui, tradition and survival on Easter Island (McCall, 1981), traducido al castellano diez años después, caracteriza esta transición entre los estudios de rescate 
y aquellos que leen la aculturación no como un proceso lineal, sino como procesos divergentes y convergentes donde emergen nuevas formas culturales (Bateson, 1972). En lugar de inventariar los cambios culturales y definir un proceso lineal de transformación social, McCall se enfocó en cómo la sociedad rapanui se adaptó a los cada vez más rápidos y constantes contactos culturales. McCall concluye que si bien existieron transformaciones mayores en ciertas áreas de la cultura, como en la religión o el sistema político, en otras esferas más íntimas persistieron ciertos aspectos culturales que permitieron la adaptación de los patrones foráneos a una nueva cultura rapanui que emergía. Así, la sociedad rapanui no desapareció porque el sistema cultural y la ingeniosidad de sus miembros permitieron modificar los modelos foráneos. McCall concluye que durante los años setenta, "por debajo de una apariencia de chilenidad se esconde un patrón cultural polinésico" (1981, p. 65), el cual puede ser observado a través de las relaciones de parentesco, el trabajo colectivo y el modelo de tenencia de la tierra.

Pensamos que el trabajo de McCall influencia dos tendencias actuales de la antropología chilena sobre Rapa Nui. En primer lugar, una que podemos denominar como antropología histórica, consistente en la recopilación y sistematización de corpus documentales, tanto para reconstruir genealogías, observar las relaciones coloniales o analizar momentos precisos de la historia rapanui (primeros contactos, evangelización, colonialismo chileno, etc.). La segunda es la valorización del presente etnográfico que da pie al análisis de temáticas específicas.

En una línea similar, aunque varios años más tarde, se inscribe el trabajo de la antropóloga holandesa, residente en Chile, Riet Delsing. Su tesis doctoral, defendida en 2009 en la Universidad de California, Santa Cruz, publicada primero en inglés (Delsing, 2015) y luego en castellano (Delsing, 2017), nos presenta un análisis general de las estrategias de resistencia, apropiación y negociación de la sociedad rapanui frente al Estado chileno. El argumento es que la sociedad rapanui ha empleado lo que la autora llama diferencia cultural como una herramienta para construir espacios de autodeterminación política. Utilizando conceptos de los cultural studies y del posestructuralismo, el trabajo de Delsing aporta con un efecto de actualidad, puesto que entrega antecedentes de los acontecimientos políticos más importantes de los últimos treinta años, como lo es la aplicación de la Ley Indígena y la creación de organizaciones de representación, como el Consejo de Ancianos, el Parlamento Rapa Nui y -en su versión revisada en español-el "consejo de clanes" Honui (Delsing, 2017).

Desde el abordaje de la resiliencia, el presente etnográfico adquiere relevancia y desde éste se analizan problemáticas particulares sobre aspectos culturales específicos. Con estos cambios paradigmáticos se deja de lado tanto el abordaje holístico de la sociedad rapanui, como lo hizo Métraux en su monografía (1971), como también las temáticas que habían sido privilegiadas por la antropología clásica, tales como el problema de los orígenes de los habitantes, las interrogantes ligadas al megalitismo y el desciframiento de las tablillas rongorongo. Estas temáticas pasan a ser campos especializados dentro de la arqueología, la bioantropología y la arqueogenética (Green, 1998, 2000; Stefan, 2001; Matisoo-Smith \& Robins, 2004), el estudio de la estatuaria (Van Tilburg, Dunn \& Sherwood, 2020), la criptología y las ciencias del 
lenguaje (e.g. Pozdniakov, 1996; Pozdniakov \& Pozdniakov, 2007; Horley, 2005, 2007; Melka \& Schoch, 2020 y una extensa bibliografía adicional), entre otras especializaciones. Si bien, el presente etnográfico comenzó a ser observado en un primer momento por investigadores extranjeros, estos poco a poco fueron dejando lugar a investigadores y estudiantes nacionales. El presente etnográfico aparece con fuerza en los trabajos que surgieron desde la academia chilena.

Cabe destacar que el enfoque del rescate memorial ha sido nuevamente puesto en valor con los reportajes de investigación realizados por la periodista Patricia Stambuk, que interroga las memorias sobre acontecimientos que tuvieron lugar hace cien años atrás (movimiento milenarista de 1914), o a fines de los años sesenta (presencia de la base norteamericana) (Ŝtambuk, 2010, 2016). Ya no se trata de reconstruir una sociedad de un pasado indeterminado, sino de salvaguardar cómo la sociedad actual procesa su propia historia. Esto parece apuntar a una problemática mayor y transversal en el tiempo, que corresponde a la temática del olvido y la preservación de la memoria.

Durante el último tercio del siglo XX observamos un doble giro paradigmático que permitió centrar el interés en el presente etnográfico, primero desde el enfoque de la aculturación como un proceso largo e inacabado, y luego, desde la perspectiva de la resiliencia y las formas performativas de crear y recrear una cultura y una sociedad rapanui. Cabe destacar que recientemente Rapa Nui comienza a ser observada desde sus interacciones con Polinesia, lo que alimenta actualmente un proceso de renacimiento cultural y reconfiguración política (Delsing, 2009; Muñoz, 2010, 2017a; Seelenfreund \& Mardones, 2018).

\section{La institucionalización de la investigación en Rapa Nui}

En la antropología como disciplina se pueden reconocer dos grandes abordajes: uno teórico, ligado tradicionalmente con la academia, que se puede remitir a la fundación de la misma, y a los diferentes enfoques que hemos desarrollado en la sección previa; y otro aplicado y vinculado con los enfoques desarrollistas que se inician en la década de 1950. En Chile, con la institucionalización de la disciplina ambos enfoques se despliegan en paralelo y se complementan.

\section{La investigación antropológica \\ desde la academia chilena}

Como ya se mencionó, la institucionalización de la antropología chilena nace con el Centro de Estudios Antropológicos de la Universidad de Chile (CEA), creado en 1954, al alero de la Facultad de Filosofía y Humanidades. Este centro antecede tanto al Departamento de Antropología de la Universidad de Concepción, fundado en 1968, y al de la Universidad de Chile (UCh), fundado en 1969 (Arnold, 1990; Garretón, 2005). A partir de la década de los noventa se abren nuevas carreras de antropología en varias universidades privadas del país pero, a pesar de ello, la investigación antropológica y arqueológica sobre Rapa Nui seguirá siendo, hasta tiempos recientes un monopolio de investigadores extranjeros.

La institucionalización de la disciplina estuvo marcada por la mirada del director del CEA, el arqueólogo norteamericano Richard Schaedel, para quien la antropología debía entenderse como una ciencia social general que abarcaba tanto la antropología física, la lingüística, la 
arqueología y la antropología social. Durante los primeros años del CEA, y dada la falta de profesionales chilenos, se promovió la venida de varios investigadores extranjeros para desarrollar sus estudios arqueológicos en Chile y formar a los futuros profesionales (Arnold, 1990). Entre los académicos que realizaron clases figuran Alfred Métraux, invitado por la Facultad Latinoamericana de Ciencias Sociales (FLACSO) en su calidad de antropólogo americanista y no como miembro de la expedición francobelga a Rapa Nui; y en 1961, William Mulloy, quien había trabajado en la isla en la restauración del primer complejo monumental (Ahu Akivi). Mulloy había formado parte en 1955-1956 de la expedición noruega.

En ausencia de antropólogos y arqueólogos profesionales en el país, la Universidad de Chile decidió enviar a los jóvenes estudiantes del CEA como acompañantes de las expediciones científicas extranjeras, esto como parte de su programa de formación y especialización. En este contexto llega a Rapa Nui, en 1955, Gonzalo Figueroa García-Huidobro para integrar la expedición arqueológica noruega y en 1957, Ruperto Vargas acompaña a Thomas Barthel en la "Expedición Etnológica Chileno-Alemana". Asimismo, en febrero de 1956, la Universidad de Chile, a través del CEA, organiza una expedición a la isla en la cual participaron Gustavo Peña, Alberto Medina, Bernardo Berdichevsky, Francisco Reyes, Carlos Munizaga, Gastón Bejarano, Eduardo Sánchez y Ottmar Wilhelm ${ }^{25}$, médico de la Universidad de Concepción y de la Armada nacional, que había estado en Rapa Nui ${ }^{26}$. También viajaron dos miembros de la Sociedad Arqueológica de Viña del Mar, Jorge Silva y Luis Strozzi. Sánchez se unió a la expedición noruega y prosiguió con ellos a las otras islas de la Polinesia oriental. Su colabora- ción quedó plasmada en un estudio comparativo de las azuelas de basalto (Figueroa \& Sánchez, 1965). De todas estas expediciones, probablemente la con mayor impacto disciplinar de largo plazo fue la noruega, dado que dos de sus miembros (W. Mulloy y G. Figueroa) dedicaron el resto de sus vidas al estudio y la protección del patrimonio arqueológico de la isla.

Durante su estadía de 18 meses en el CEA (entre 1959 y 1961), William Mulloy estuvo más de un año en la isla trabajando de la mano con Gonzalo Figueroa en la primera restauración de un sitio monumental. Durante la otra parte de su estadía (en 1961) fue docente en la Universidad de Chile en Santiago. Desde mediados de los años setenta, Mulloy contó en sus trabajos con la participación de estudiantes de arqueología formados tanto en la Universidad del Norte como en la Universidad de Chile. Primero, Calogero Santoro, quien participó en la restauración de la aldea de ceremonial de Orongo; luego Claudio Cristino y Patricia Vargas se encargaron de continuar con el programa de prospección arqueológica iniciado por Mulloy en 1973. Posteriormente, ambos arqueólogos fueron parte del Instituto de Estudios de Isla de Pascua de la Universidad de Chile.

Al mismo tiempo que Cristino y Vargas llegaban a la isla, regresaba a ella, como director del Museo, Sergio Rapu Haoa. Rapu fue el primer arqueólogo rapanui, formado inicialmente como museólogo en el programa de formación técnico-profesional al interior del Museo Nacional de Historia Natural, y que luego continuó estudios en las universidades de Wyoming y de Hawaii, patrocinado por Mulloy. A lo largo de estos años, los estudios arqueológicos opacaron en gran medida las investigaciones en antropología social. 
La arqueología chilena en Rapa Nui entre los años setenta y ochenta consistió principalmente en la prospección emprendida por el equipo del Instituto de Estudios de Isla de Pascua (IEIP) que derivó en la publicación de un atlas con la ubicación de los sitios arqueológicos, aunque sin su identificación, y muchos años después en un libro sobre los patrones de asentamiento (Vargas, Cristino \& Izaurieta, 2006). En este periodo también se realizaron proyectos de conservación y de restauración desde el museo con el apoyo de la Dirección de Bibliotecas, Archivos y Museos (DIBAM) y financiamiento del gobierno regional ${ }^{27}$. Se trata de la puesta en valor de los sitios monumentales como Ahu Nau Nau y Ahu Tautira, una pequeña excavación y la conservación de las pinturas de la cueva de Ana Kai Tangata y luego un proyecto de estudio de restos humanos en conjunto con la Universidad de Wyoming ${ }^{28}$ (Seelenfreund, 1988, 2000; CerveIlino, 1993; Seelenfreund \& Holdaway, 2000; Gill, 2000; Shaw, 2000a, 2000b). De los resultados de las excavaciones en Ahu Nau Nau solo contamos con los análisis de los restos humanos desarrollados por el equipo de la Universidad de Wyoming (Gill \& Owsley, 1993; Gill, 2000). Con posterioridad a los años noventa, ya prácticamente no vemos involucramiento de la academia chilena en proyectos de investigación en la isla, y los escasos estudios realizados fueron llevados a cabo por el equipo del IEIP de la Universidad de Chile. El resto de los esfuerzos estuvo orientado principalmente a la conservación de la estatuaria (Bahamóndez, 2000).

Una repercusión directa de interés arqueológico es que, a partir de los años setenta, un pequeño número de estudiantes rapanui ingresaron a estudiar esta disciplina en la Universidad de Chile. De estos solo una estudiante continuó ejerciendo, trabajando siempre en asociación con los equipos internacionales. Recién en 2013 se tituló la primera arqueóloga rapanui en una universidad chilena (Universidad Internacional Sek), pionera de una nueva generación de profesionales isleños. Hoy, la isla cuenta con seis profesionales rapanui (en arqueología, bioantropología y antropología social) graduados en instituciones nacionales. La mayoría trabaja en la gestión patrimonial o en consultorías de impacto ambiental. Destacamos que la actual gobernadora provincial, Tarita Alarcón Rapu, es una de ellas. A la fecha, no vemos aún el involucramiento de los profesionales jóvenes en el ejercicio académico.

Una forma de acceder al desarrollo de la investigación chilena contemporánea sobre Rapa Nui es a través de las tesis de pregrado y de posgrado realizadas. Resulta interesante preguntarse por cuáles eran las temáticas de estudio durante la fase de institucionalización e identificar el lugar que los estudios sobre Rapa Nui ocupaban. Si bien la institucionalización de la antropología en Chile no significó un aumento considerable de investigaciones sobre Rapa Nui, esto cambia entrado el siglo XXI.

Arnold (1990) desglosa las temáticas de las tesis realizadas en la Universidad de Chile para el periodo 1977-1987; del total de 84 tesis de pregrado de antropología social, solo dos corresponden a estudios "pascuenses" (Cristino, 1979; González, 1984). Estas tesis fueron realizadas por estudiantes del programa de prospección arqueológica iniciado en la década de 1970 por Mulloy (Arnold, 1990). Adicionalmente, hubo una tesis de arqueología (Seelenfreund, 1980). Por otra parte, hemos podido determinar que entre 1979 y 1990, considerando todas las instituciones que imparten la carrera de antropología y sus subdisciplinas en Chile, solo cinco 
tesis abordaron temas de antropología, arqueo- son de la Universidad de Chile (Figura 1). logía o historia rapanui, de las cuales la mayoría

Figura 1. Distribución de tesis en temáticas de antropología social, arqueología o historia producidas en universidades chilenas entre 1979 y 2020.

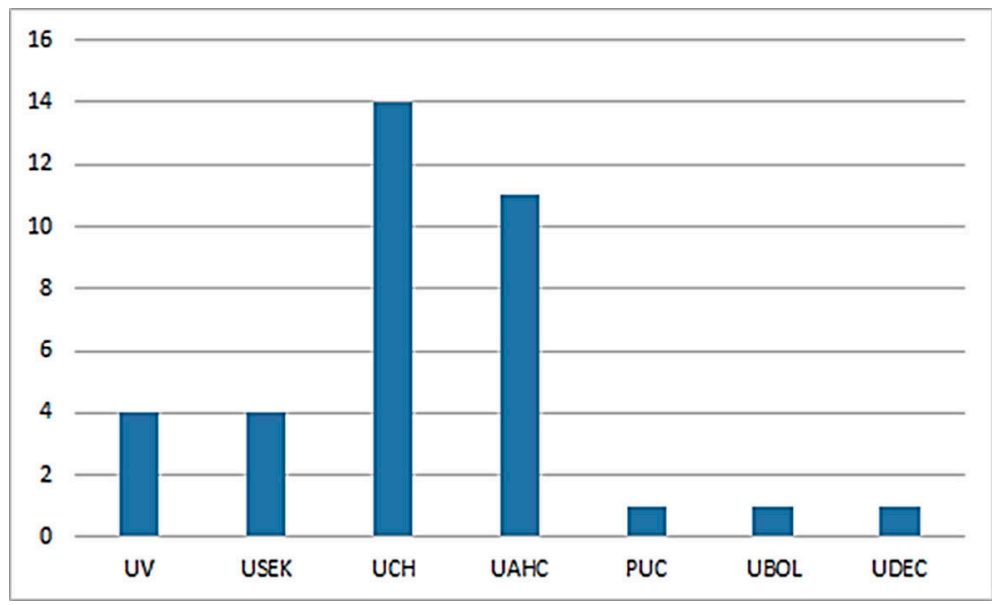

Elaboración propia.

Revisemos en detalle las tesis producidas durante este período. La primera tesis de arqueología en una universidad chilena sobre un tema rapanui se defiende en 1979 (Cristino, 1979) y la primera en antropología se realiza en 1980 (Cuadra, 1979). En toda la década de los años ochenta solo se defienden dos tesis (González, 1984; Santibañez, 1986), reflejo tanto de las dificultades de viajar en aquellos años a la isla, como de la distancia con la cual se veía dicho territorio y sus habitantes. Hay un extenso vacío en cuanto a producción de tesis hasta mediados de los años noventa, sin duda producto del cierre de los centros de estudios y del exilio de varios académicos durante la dictadura militar. En 1996 y 1997 dos estudiantes de historia en la Universidad de Valparaíso, ambos alumnos de Jorge Silva, reavivan los estudios sobre la historia contemporánea de Rapa Nui (Castro, 1996; Grifferos, 1997).
Cuando analizamos la distribución de las tesis por decenios observamos un aumento significativo de las mismas a partir del año 2000 (Figura 2). Estas se reparten casi por igual entre la UCh y la Universidad Academia de Humanismo Cristiano (UAHC). Destacamos que el desarrollo de la investigación antropológica realizada por tesistas de pregrado en este período está signado por los esfuerzos más bien individuales de algunos académicos, como Mónica Weisner, en la Universidad de Chile, Jorge Silva, en el Departamento de Historia en la Universidad de Valparaíso, Andrea Seelenfreund, en la UAHC y en la Universidad Internacional Sek (USek) y, más recientemente, por Rolf Foerster, también en la Universidad de Chile.

En el caso de las cuatro tesis de la UCh del decenio 2000-2010, dos están directamente 
vinculadas al proyecto de investigación de Weisner sobre temáticas de antropología médica (Fajreldin, 2002; Leyton, 2004). Otra de las tesis versa sobre educación y crianza (Zurob, 2009), mientras que la última solo se relaciona tangencialmente con Rapa Nui (Menares, 2004). Simultáneamente, las seis tesis defendidas en la UAHC en el decenio 2000-2010 están directamente asociadas al fomento del estudio de la insularidad que la Escuela de Antropología de dicha institución comenzó a desarrollar. Así, los temas abarcan desde las artes performáticas y la Tapati Rapa Nui (Andrade, 2004), la relación comunidad-museo (Budinich, 2006), la migración y la etnicidad urbana (Muñoz, 2007), las discusiones en torno a la autonomía (Escobar \& Lagos, 2009), la alimentación (Ramírez, 2010) y el etnopaisaje (Torres, 2010). Solo una tesis de pregrado se registra en la Universidad de Valparaíso (Delaire, 2005). De este análisis podemos concluir que recién a partir del año 2002 observamos un aumento sustantivo en las investigaciones de pregrado.
De las tesis producidas en el decenio 2011-2020, casi todas están vinculadas a dos proyectos de investigación financiados por fondos estatales (FONDECYT), uno alojado en la UCh a cargo del profesor Rolf Foerster y el otro en la UAHC dirigido por la académica Andrea Seelenfreund. Dos de las cuatro tesis de la UCh producidas en este periodo se vinculan al proyecto de Foerster (Garrote, 2013; Alvear, 2014). Una está vinculada al proyecto de investigación de Seelenfreund en la UAHC (Charó, 2014) y la cuarta (Arias, 2011) fue autofinanciada y gestionada por la estudiante. Al mismo tiempo, en la UAHC, las cinco tesis del período se vinculan a proyectos (FONDECYT y FONDART) de Seelenfreund (Rojas, 2014; Arriagada, 2015; Mardones, 2016; González, 2017). En forma paralela, las cuatro tesis registradas para la USek entre 2011 y 2020 fueron dirigidas por Andrea Seelenfreund (Atam, 2012; Astete Paoa, 2014; Rapu, R., 2017; Berenguer, 2018). Las temáticas abordadas en las tesis se muestran en la Figura 3.

Figura 2. Número de tesis en antropología/arqueología e historia distribuidas por decenios.

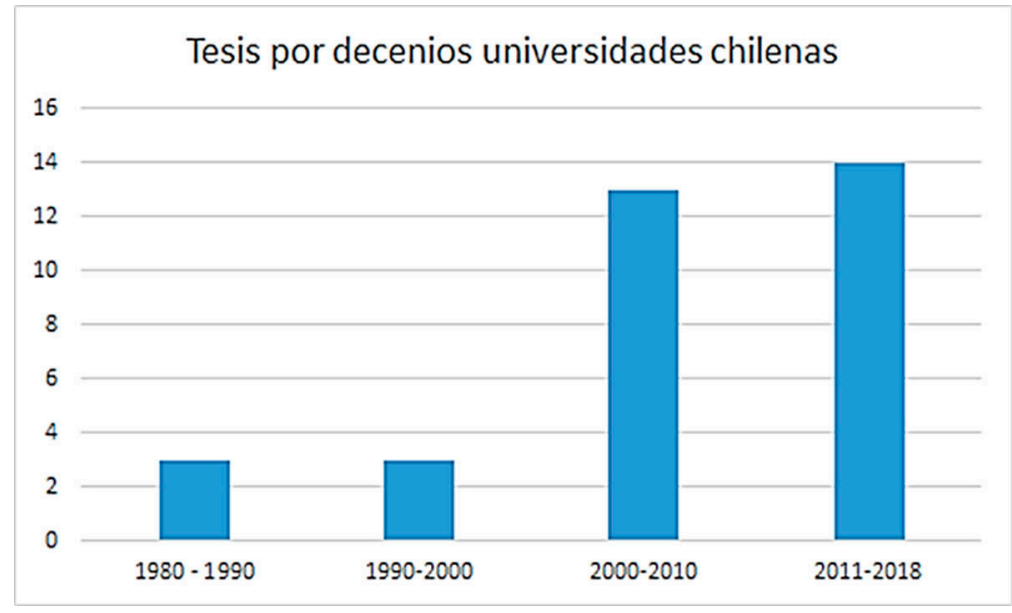

Elaboración propia. 
Cabe destacar que actualmente, las tesis sobre temas rapanui son desarrolladas sobre todo por investigadores nacionales y estudiantes de pregrado en universidades chilenas (Universidad de Chile, IsLab en la UAHC), como por investigadores nacionales desde el extranjero en el marco de estudios de posgrado (Francia, Alemania, Estados Unidos, España, Nueva Zelanda y Uruguay).

En cuanto al registro internacional de tesis doctorales o de magíster identificamos un primer momento entre los años 1963 y 1978. Se trata de trabajos realizados por estudiantes de arqueología norteamericanos que acompañaron a Mulloy en sus sucesivas campañas de excavación y restauración de sitios monumentales.
A partir de 1967, con el aumento de las frecuencias de vuelos, empezamos a observar a los primeros jóvenes antropólogos sociales en la isla. La primera tesis de doctorado fue realizada por el norteamericano Grant McCall y data de 1976. La primera tesis sobre un tema rapanui escrita y defendida por una antropóloga chilena en el extranjero data de 1993 y fue realizada por Susana Rochna-Ramírez (1992), con base en datos recogidos en la isla a fines de los años ochenta. En su trabajo, Rochna-Ramírez compara las políticas públicas aplicadas en Rapa Nui y aquellas desarrolladas en Chile continental y Costa Rica. Recién en 2009 encontramos una tesis en antropología, que si bien fue defendida en una universidad extranjera, fue escrita por la antropóloga holandesa residente en Chile, Riet Delsing (2009).

Figura 3. Dispersión temáticas de las tesis de pregrado y doctorado defendidas en universidades chilenas entre 1979 y 2018.

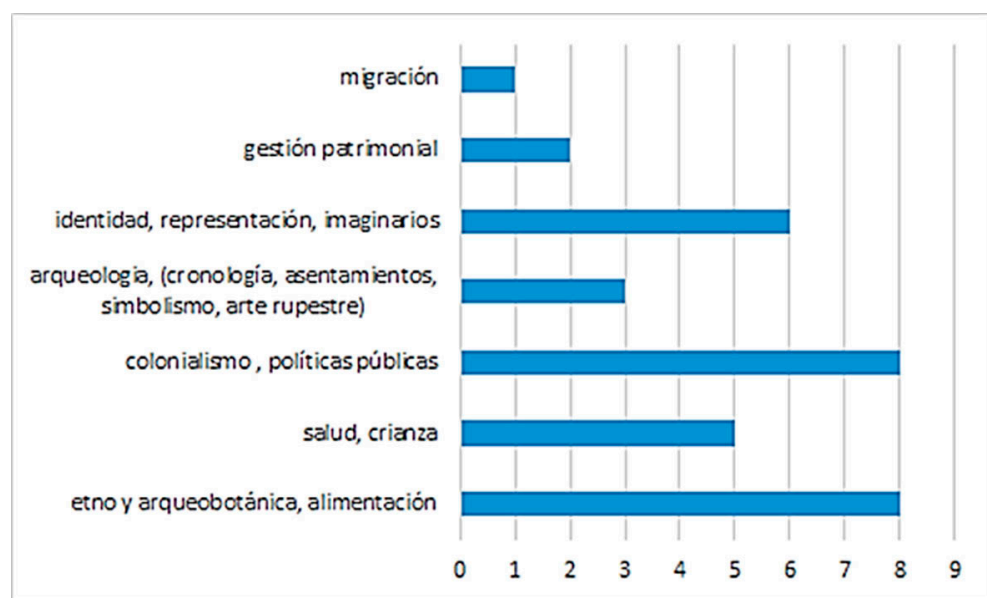

Elaboración propia.

A partir de 2010 las tesis de posgrado se multiplican y son realizadas en su totalidad por jóvenes investigadores chilenos. En parte, este aumento en los estudios sobre Rapa Nui es el resultado de la implementación de programas de becas a través de CONICYT, que financian 
estudios de posgrado en el extranjero. Entre 2010 y 2020 se defendieron en total siete tesis, tanto de maestría como de doctorado (Muñoz, 2010; Arthur, 2012; Faba, 2012; Arthur, 2015; Rivas 2017; Muñoz, 2017a), más del doble que todas las tesis defendidas por investigadores extranjeros en veinte años ${ }^{29}$.

Hemos observado también un progresivo aumento en las publicaciones académicas, ya sea en formato de libro de uno o varios autores, compilación de artículos independientes en torno a uno o varios temas, compilaciones de documentos de archivo y también, artículos publicados en revistas académicas. En efecto, entre 1980 y 1990 se publicó un solo libro en Chile, referente a la arqueología de la isla y solo cuatro artículos en español. En los decenios entre 1990 y 2009 y 2010-2019, el número de libros aparecidos aumentó a siete y también hubo un importante aumento en la cantidad de artículos. Ya en la última década hemos visto una explosión en la publicación de libros (Tabla 1, Figura 4). Estos son producto, en parte, de proyectos de investigación iniciados en esta década, pero también del trabajo de intelectuales jóvenes formados en antropología e historia en Chile que comienzan a publicar sus investigaciones.

Tabla 1: Publicaciones en español sobre Rapa Nui en temáticas antropológico-sociales en los últimos cuarenta años

\begin{tabular}{|c|c|c|c|c|c|}
\hline & Artículos & Libros & $\begin{array}{c}\text { Capítulos } \\
\text { en libros }\end{array}$ & $\begin{array}{c}\text { Traducciones } \\
\text { de libros }\end{array}$ & $\begin{array}{c}\text { Libros } \\
\text { compilados }\end{array}$ \\
\hline $\mathbf{1 9 8 0}-\mathbf{1 9 8 9}$ & 4 & 1 & 0 & 0 & 0 \\
\hline $\mathbf{1 9 9 0}-\mathbf{1 9 9 9}$ & 4 & 7 & 0 & 0 & 0 \\
\hline $\mathbf{2 0 0 0}-\mathbf{2 0 0 9}$ & 19 & 7 & 5 & 3 & 0 \\
\hline $\mathbf{2 0 1 0}-\mathbf{2 0 1 9}$ & 17 & 23 & 52 & 2 & 4 \\
\hline
\end{tabular}

Fuente: Elaboración propia.

Figura 4. Libros y artículos publicados en Chile y en el extranjero en español sobre temáticas Rapa Nui.

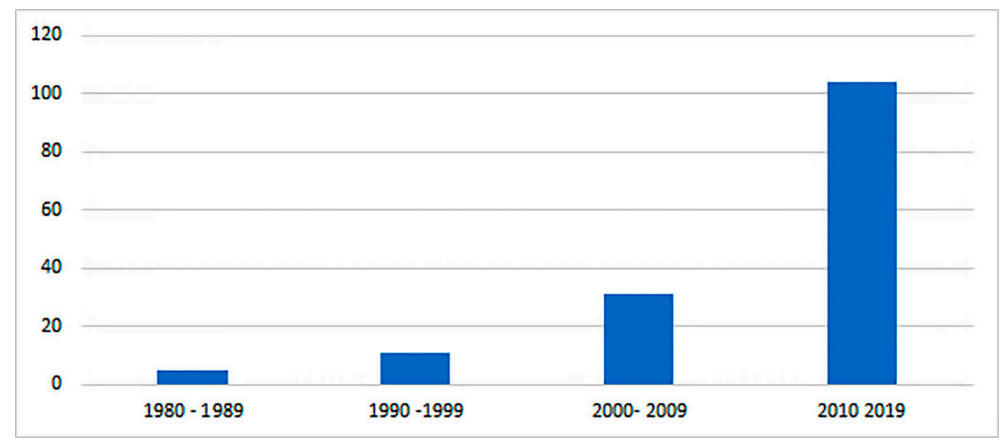

Elaboración propia. 
Relacionado a lo anterior, identificamos un creciente interés editorial por Rapa Nui. Un importante aliciente fue la creación de la editorial especializada Rapa Nui Press, que activamente ha salido en búsqueda de manuscritos, ha reeditado antiguos libros y traducido al castellano otros tantos. Otras editoriales, LOM, Ocho Libros, Pehuén y Catalonia, han publicado libros sobre Rapa Nui en el marco de colecciones sobre temas indígenas y antropológicos. Todo esto muestra el creciente interés editorial que la isla representa.

En cuanto a los artículos científicos, el principal referente para investigaciones sobre Rapa Nui hasta inicios del siglo XXI, fue el Rapa Nui Journal, publicado en Estados Unidos por la Easter Island Foundation y fundado por la arqueóloga Georgia Lee. Una revisión de todos sus volúmenes (entre 1985 y 2016) nos muestra que son pocos los antropólogos chilenos que han publicado en ella. En sus primeros números contó con algunas contribuciones de arqueólogos e historiadores chilenos que residían en la isla, pero recién a fines de los noventa vemos los primeros artículos alejados de los temas arqueológicos. Se trata de los trabajos de Arredondo (2000a, 2000b) sobre la temática de género desde una perspectiva antropohistórica, en concordancia con el surgimiento de este objeto de estudio en Chile continental.

Finalmente, destaquemos que los trabajos sobre Rapa Nui son escasos en los congresos organizados por el Colegio de Antropólogos o la Sociedad Chilena de Arqueología. Recién en 2001, en el IV Congreso Chileno de Antropología, Mónica Weisner y Valentina Fajerldin presentan los resultados de sus investigaciones en antropología médica (Weisner \& Fajreldin, 2003) y solamente en el congreso de 2007 aparece una mesa exclusiva sobre investigaciones en Rapa Nui. En tanto, la participación de investigadores chilenos en los congresos organizados por la Easter Island Foundation (EIF) se inicia en 1996 en el Congreso de Albuquerque. En esa ocasión presentaron sus investigaciones la antropóloga rapanui Paloma Huke, la antropóloga Riet Delsing y la historiadora Alejandra Grifferos. Posteriormente, en el congreso del año 2000, vemos solo dos expositores, Grifferos y Delsing. En el congreso de 2004, realizado en Viña del Mar, hubo una mesa dedicada a temas sociales e históricos en la cual participaron en forma activa estudiantes de la UAHC y otros antropólogos nacionales. Ya en 2012, en el evento en California, con la invitación que la EIF hace a varios estudiantes, identificamos un aumento de trabajos presentados por investigadores jóvenes chilenos, entre los que se encuentran varios rapanui. Esta tendencia se mantiene hasta el Congreso de 2015, celebrado en Berlín, el cual contó con una importante delegación de investigadores rapanui y antropólogos chilenos. Los temas presentados en dicha ocasión reflejan la diversidad de temáticas en que se desarrolla actualmente la investigación sobre Rapa Nui: educación, historia, gestión de patrimonio, cine antropológico, antropología médica, antropología histórica y arqueología. Con estos datos sobre la producción intelectual vemos cómo los estudios sobre Rapa Nui se instalan en forma sistemática a partir del nuevo siglo en la antropología chilena. 


\section{La aproximación antropológica}

desde los servicios públicos

En el contexto del retorno a la democracia, el Colegio de Antropólogos se articuló con algunas Organizaciones No Gubernamentales (ONG) para la defensa de los derechos humanos y de los pueblos indígenas. La sección "Minorías Étnicas" del Colegio organizó en 1987 y 1988 dos seminarios en esta materia e invitó a una delegación rapanui. Asistieron a estos encuentros un joven Petero Edmunds $\mathrm{Paoa}^{30}$ $y$, al año siguiente, Alberto Hotus Chávez ${ }^{31}$. A partir de entonces, según Susana Rochna-Ramírez ${ }^{32}$, ambos líderes rapanui se vinculan con dirigentes de otros pueblos indígenas del país. En febrero de 1990, un grupo de estudiantes de antropología de la Universidad de Chile (entre ellos Rochna-Ramírez y Felipe Domb), auspiciados por la ONG Grupo de Estudios Agrorregionales (GEA), organiza el Primer Congreso para el Desarrollo de Isla de Pascua. En este se discutieron temas como la tenencia de tierra, el manejo del patrimonio, la tuición de estos por parte de la Corporación Nacional Forestal (CONAF) y aspectos sobre educación. Todos estos temas mantienen su relevancia en las políticas actuales de la isla.

Algunos antropólogos del Colegio acompañaron el proceso político interno rapanui, en el que aparece como referente el Consejo de Ancianos Rapanui y la figura de Alberto Hotus Chávez, y cuya principal demanda es la recuperación del dominio de las tierras. En este proceso jugó un papel importante la antropóloga Susana Rochna-Ramírez, quien aportó al debate y a la construcción de una sensibilidad interna sobre el tema, así como a la difusión en Chile sobre este problema ${ }^{33}$.
Posteriormente y considerando que el tema de la tierra ya se encontraba debidamente instalado, la promulgación de la Ley 19.253, conocida como Ley Indígena, constituye otro hito importante en el Chile posdictadura. Gravitante, aunque de manera diferente a lo ocurrido con el pueblo mapuche, esta ley marca un giro en la política pública en el territorio rapanui, hasta entonces regido solo por la Ley 16.441.

Mientras que en el continente, y en particular con el pueblo mapuche, el modelo de implementación de la ley se centró en un enfoque desarrollista y culturalista -a través de la acción de la CONADI en la compra de tierras a particulares en beneficio de comunidades indígenas-, en el caso rapanui la aplicación de la ley conoció importantes divergencias. En la isla aparecen dos facciones, una a favor de la inclusión de los rapanui en la ley y otra que impulsaba la generación de una ley especial ${ }^{34}$. Mediante una delicada negociación de los representantes rapanui con senadores y diputados, se definió la inclusión en esta, aunque con importantes artículos privativos ${ }^{35}$. La política pública chilena en Rapa Nui aparece así, de la mano de la CONADI y de la Comisión de Desarrollo de Isla de Pascua (CODEIPA), instituciones que poco a poco se han ido empoderando a través de la participación cada vez más importante de rapanui en las jefaturas de los servicios públicos insulares.

Es notorio que en la década de los noventa los organismos públicos comienzan a contratar a antropólogos y arqueólogos en áreas especializadas (patrimonio, gestión del parque, políticas indígenas) ${ }^{36}$. A partir de 2010 , se promueve en forma activa que las jefaturas de los servicios sean rapanui, de modo que muchos de estos cargos han pasado a mano de la primera 
generación de profesionales formados en el continente. A nuestro modo de ver, se trata de la consolidación de lo que Andueza (2000) llamó la "rapanuización" de la política pública ${ }^{37}$.

En el marco del empoderamiento de la comunidad rapanui respecto de sus instituciones y procesos de articulación internos, varios antropólogo(as) han prestado asesorías y colaborado en la instalación de instrumentos de gestión y de metodologías con adaptaciones locales, lo que ha impulsado la conformación de instancias administrativas o políticas dentro de la propia comunidad. Destacamos los casos de los antropólogos Cristian Potoczniak y Javiera Luco, quienes en los años noventa realizaron una serie de microasesorías de desarrollo local a través de proyectos y fondos de la Corporación de Fomento de la Producción (CORFO). Estas estaban orientadas al desarrollo del turismo y derivaron en la creación de la oficina Tarai Henua, que llegó a ser un referente de desarrollo local en la articulación de nuevos empresarios en la primera mesa directiva de la Cámara de Turismo ${ }^{38}$.

En los últimos diez años, podemos observar cómo las instituciones, ya dirigidas por actores locales, se interesan en contar con asesorías antropológicas en temas puntuales, tales como el patrimonio, la salud, las tierras, la lengua y la educación. Desde la doble agencia, académica y aplicada, se han efectuado consultorías para instituciones como el Ministerio de Salud, el Hospital Hanga Roa (Weisner \& Fajreldin, 2003, 2005; Dides, Pérez, Fajreldin, Soto \& González, 2005; Sadler et al., 2006; Fajreldin, 2002, 2012, 2017, 2020) y el Consejo de Monumentos Nacionales, en particular en lo que refiere a repatriación de ancestros rapanui (Arthur, 2018, 2020).
También encontramos el caso de antropólogas residentes que realizan sus actividades profesionales, como Lilian González, que desde 1998 ha estado ligada al desarrollo de la educación intercultural; Camila Zurob, quien se desempeñó en Bienes Nacionales y posteriormente en los ámbitos educativo y museístico; o el caso de Paulina Torres, que ha trabajado en Bienes Nacionales y que actualmente se desempeña en la Secretaría Técnica del Patrimonio Cultural.

Desde 2008, siguiendo los lineamientos de la UNESCO, los gobiernos de la concertación comienzan a desarrollar políticas de protección del patrimonio inmaterial ${ }^{39}$. Para el caso rapanui, esto ha significado ampliar el repertorio de bienes patrimoniales que ya se no limitan al potencial arqueológico, que fue el gran modelo de desarrollo hasta los años noventa. El Consejo Nacional de la Cultura y las Artes crea el Área de Patrimonio Inmaterial y abre una línea de puesta en valor de oficios y saberes a través del programa Tesoros Humanos Vivos. También se promueve el levantamiento de líneas de base para el trabajo sistemático sobre estos criterios, donde antropólogos sociales han tenido un rol importante ${ }^{40}$. En este contexto, la Secretaría Técnica ha definido un Plan Maestro de Patrimonio Rapanuii1, con la participación de la comunidad en la definición de acciones con sentido territorial y estrategias de comunicación y difusión permanentes. Este trabajo, según Paulina Torres ${ }^{42}$, se inspira en iniciativas y enfoques desarrollados en otras islas de la Polinesia, como el Código Ético de Aotearoa/ Nueva Zelanda.

El eje ya no está centrado en la colección y protección, sino en la articulación del patrimonio material con la comunidad, basado en 
un enfoque de derechos. Asimismo, se ha avanzado en la línea de trabajo de la restitución tanto de restos humanos como de piezas de arte y artesanía antiguas que se encuentran fuera de la isla. En la actualidad, esta línea de trabajo ha consistido principalmente, en la compra de tallados de madera que datan de finales del siglo XIX y principios del siglo $X X$ por parte del museo. También ha incluido la restitución de restos humanos. Este trabajo posee para la comunidad un innegable valor de carácter político y simbólico debido al mana del cual son depositarios ${ }^{43}$. Destaca en esa labor el trabajo realizado por Jacinta Arthur junto a la líder rapanui Piru Hucke Atan, que llevaba años registrando los objetos rapanui repartidos en los museos del mundo (Arthur, 2020).

\section{Los rapanui en la antropología chilena: de informantes a autores}

Hemos señalado que junto al surgimiento de la antropología académica, realizada en un primer momento por investigadores extranjeros, surgió en Rapa Nui el oficio de informante: un experto en temas del pasado. Schorch et al. (2020) analizan al informante rapanui como una figura ambigua, vinculada a la temporalidad de la información transmitida, pero también a la noción de secreto de esta. El informante es, en este sentido, un actor en la producción de información. Nosotros diremos que es también un autor de esta.

Al analizar las figuras del informante rapanui, Schorch et al. (2020) identifican dos ramas: una compuesta por personas nacidas antes de la llegada de los misioneros y de los cuales Routledge pudo conocer a los últimos. Estos ancianos, en el momento mismo de la investi- gación etnográfica, instruyeron a personas más jóvenes, como lo fue Juan Tepano. De esta segunda generación saldrán los informantes de Métraux, Englert, Barthel e incluso McCall. Por otra parte, Schorch et al. (2020) indican una segunda rama, desconocida por Métraux, correspondiente a los ancianos recluidos en el leprosario, quienes, al igual que los ancianos de Hanga Roa, transmitieron información a una generación más joven, que serán informantes de Englert.

Si bien todos los investigadores posteriores a Routledge trabajaron con la segunda generación de informantes, los ancianos recluidos en el leprosario nunca estuvieron totalmente aislados de la generación de los jóvenes de Hanga Roa. Por ejemplo, Simón Hereveri Vaka, quien entregó la versión más completa de la leyenda de Tuki Haka Hevari a Métraux, tuvo a su abuelo materno, Tomenika Vaka Tukuonga, uno de los informantes de Routledge, en el leprosario. Lo mismo puede ser dicho de Carlos Teao Tori, otro de los jóvenes informantes de Routledge y Métraux, cuyo hermano Arturo Teao Tori fue el informante de Englert. Arturo fue internado en el leprosario desde su juventud. Otra figura importante de la segunda generación de informantes conectados a los ancianos del leprosario fue Juan Araki Bornier, cercano al obispo Edwards en 1911 y pariente de uno de los informantes de Routledge: Arakilo Pua Ara Hoa, autor supuesto del Manuscrito E. Victoria Rapahango es otra de las personas que forjó su reputación de informante al colaborar estrechamente con Métraux, Barthel, Campbell y McCall. Los hermanos Pakarati Rangitaki (hijos del catequista formado en Moorea, Nicolás Pakarati y de la mujer originaria del atolón de Fangatau en las Tuamotu, Elizabeth Rangitaki) y las ramas familiares Tepano Pakarati y Pakarati Atan fueron siempre 
particularmente abiertas a la transmisión de información, la que seguramente era una mezcla de saberes rapanui y paumotu ${ }^{44}$. Otros fueron los hermanos Simón, Mateo y Gabriel Hereveri Vaka; este último internado en el leprosario e informante en 1964 del explorador francés Francis Mazière. Las familias Hito y Pate (estos últimos descendientes también de Tomenika) fueron los principales informantes de Campbell.

Algunos de los ancianos recluidos en el leprosario utilizaron métodos occidentales de conservación y transmisión de información, como lo fue la transcripción de leyendas, genealogías y otras informaciones en cuadernos, como lo develó Barthel (1965). Estos manuscritos fueron escritos en su propia lengua, pero en caracteres latinos. Se conocen seis de estos, cinco identificados y fotografiados durante la expedición noruega de 1955 (Barthel, 1965) y un sexto identificado recientemente (Horley \& López, 2014). En 2006 fue publicada una primera traducción al español del Manuscrito E (Alarcón, 2008), que sacó del olvido esta versión del poblamiento que solo aparece transcrita al rapanui en el libro de Barthel (1978) y que circuló por años en Rapa Nui como fotocopia. Recientemente se publicó una nueva traducción que ha convertido a este texto en una narración canónica del pasado de la isla (Ramírez \& Hotus, 2017).

El fenómeno de los "manuscritos rapanui" no ha sido abordado desde la antropología chilena, pero demuestra el interés profundo de los rapanui por registrar y transmitir a las nuevas generaciones su propia historia. Son, de esta manera, un ejemplo de una nueva relación con el pasado comparable al archivo. Existen otros ejemplos relevantes de esta transformación de informantes a autores. Podemos mencionar los talleres de escritura organizados en los años ochenta por los misioneros protestantes del Instituto Lingüístico de Verano, Nancy y Robert Weber, con la colaboración de la Universidad de Valparaíso, en el marco de los esfuerzos de recuperación de la lengua, donde varios rapanui escribieron sobre su propia historia (Pate et al., 1986). A nuestro juicio, se genera aquí un nuevo impulso en la escritura por los rapanui, para los rapanui y en rapanui.

Al día de hoy, varios rapanui han participado como expositores en los congresos de la EIF -en especial en los congresos de 1996, 2004 y 2015- y han publicado libros y artículos, siendo esto la culminación del proceso en el cual se transforman de informantes en autores. Podemos distinguir dos tendencias: escritos con un enfoque académico y otros con un enfoque memorial. Si bien ambas tendencias se cruzan, los objetivos son diferentes. En el primer caso, se trata de divulgación de resultados de investigaciones sobre historia colonial y las relaciones entre rapanui, la Compañía Explotadora de Isla de Pascua y el Estado desde un enfoque antropo-histórico. Podemos destacar en este enfoque los trabajos de la antropóloga Paloma Huke y del historiador Cristián Moreno Pakarati (Huke, 2011; Moreno Pakarati, 2011a, 2011b, 2013). En el segundo caso se trata, una vez más, del rescate memorial. Pensamos que este enfoque es una prolongación de los antiguos manuscritos y del paradigma rescatista que encontró eco en el mundo editorial (Hotus \& Consejo de Jefes Rapanui, 1988; Pakarati, 2011, 2016; Tepano, 2015; Pakarati, Paoa \& Madariaga, 2018; Haoa, 2010). Otros textos recientes han abordado temas de crianza y sexualidad desde una perspectiva patrimonial (Rapu, 2017), la valoración comunitaria del patrimonio arqueo- 
lógico (Nahoe, 2017) o la modificación de los currículums escolares y la enseñanza y preservación de la lengua (Haoa, 2009, 2017).

La relevancia contemporánea del Manuscrito $E$, así como de otros textos académicos o memoriales, vuelve a plantear el dilema del informante en términos de cuál es la información que se transmite a los investigadores, cuál es la que se conserva como secreto y cuál se transforma en fundamentos de la memoria contemporánea. Pero también, cuál es la información que en un momento dado interesa más a los investigadores y cuál es la que estos han aportado a los mismos rapanui en la comprensión de su pasado y su presente.

Muchos rapanui han aprendido aspectos sobre su propia historia y valorado sus prácticas culturales a través de la atención dada por los investigadores. Este interés por los temas culturales comienza a ser una constante en las relaciones entre informantes e investigadores(as), lo que ha desembocado en una relación de tipo especular, muchas veces tensionada entre la producción de los saberes, su apropiación y el uso de los mismos. Con frecuencia los informantes rapanui se proyectan en el interés de los temas actuales de la antropología y transmiten información permitiendo que la propia comunidad haga suyos no solo los discursos de los y las antropólogas, sino que logre observar ciertas temáticas como relevantes para ser trabajadas de manera teórica o aplicada por ellos(as) mismos(as).

Esta transformación del rapanui de informante a autor es uno de los cambios mayores en la aprehensión de Rapa Nui como objeto científico. Por años los antropólogos y arqueólogos han influido en las nociones que la comunidad isleña tiene sobre su pasado y también sobre sus fenómenos contemporáneos. La revalorización del pasado monumental, la reapropiación patrimonial, así como las lecturas sobre el valor del patrimonio inmaterial emergen desde la relación dialógica, no exenta de tensiones, entre investigadores, informantes e instituciones. Hoy en día, pensamos que esta nueva generación de autores rapanui tiene el potencial de identificar sus propios temas, problemáticas y eventuales soluciones al articularlos con la dimensión de las políticas públicas. Ello genera un círculo virtuoso entre quienes estudian, publican y a la par, están empoderados en las instituciones isleñas como técnicos o directores.

\section{Conclusiones}

En este artículo hemos identificado y analizado las principales tendencias y características de la antropología chilena sobre Rapa Nui, esperando contribuir al debate y a los estudios sobre la cultura y la sociedad rapanui, así como a la reflexión sobre la antropología chilena. Hemos podido apreciar que en su trayectoria los estudios antropológicos sobre Rapa Nui han conocido dos grandes focos de interés, que se han desarrollado dentro de una historia paradigmática que se desliga de la antropología chilena en general.

Durante su fase pre-universitaria, el interés antropológico se inscribe en el paradigma general del naturalismo, el que deriva rápidamente en investigaciones de "rescate" de los vestigios de una supuesta cultura ancestral y de una sociedad en vías de desaparición. Este paradigma caracterizó las investigaciones antropológicas durante la primera mitad del siglo XX. Rapa Nui planteó interrogantes particulares que 
se intentaron responder a través del rescatismo: el origen de sus habitantes, el significado del megalitismo y el desciframiento de los signos rongorongo. El interés estaba centrado en una sociedad de un pasado que resultaba indefinido. Rapa Nui se inscribe además, dentro de grandes interrogantes sobre las sociedades del Pacífico y fue principalmente abordada por investigadores extranjeros a través de vastas misiones científicas. Esta característica nos permite entender por qué en la etnografía clásica, a excepción de Routledge, el presente etnográfico aparece descuidado y por qué durante toda la primera mitad del siglo XX la cuestión étnica-social, principal paradigma antropológico en Chile continental, no fue abordado en Rapa Nui. La investigación que inaugura el ingreso de la antropología chilena en Rapa Nui estudió el fenómeno de la aculturación y no "la cuestión social", como lo hacía la antropología en Chile continental.

La antropología contemporánea se desarrolla desde la perspectiva de la resiliencia, lo que ha dado lugar a una fragmentación temática. Sin embargo, identificamos que el paradigma rescatista y en menor medida el de la aculturación, no terminan de agotarse, sino que aparecen leídos desde el ángulo de la resiliencia. En el quehacer antropológico nacional la presencia de investigadores chilenos jugó un rol secundario durante las misiones extranjeras de la segunda mitad del siglo XX. Pero esta relación se invierte entrado el siglo XXI, cuando la investigación en antropología social sobre Rapa Nui se realiza desde Chile o por investigadores chilenos desde el extranjero. Al mismo tiempo, la sociedad insular ya no se observa de manera holística, sino que desde problemáticas precisas: medicina, migraciones, identidades, política, etc. Por otra parte, desde el giro indigenista de las políticas públicas en el Chile posdictadura, observamos la participación activa de antropólogos sociales en algunas instituciones o realizando consultorías. Una nueva generación de jóvenes antropólogos ha centrado su interés y desarrollado sus carreras académicas y actividades profesionales en temas relativos a la isla. Como resultado de ello, vemos hoy una proliferación de publicaciones e involucramientos de esta nueva generación que levantan una diversidad de temas, en los que, a la par de rescatar saberes y prácticas, se acercan a los fenómenos estudiados con enfoque crítico y afán colaborativo con la comunidad.

Pensamos que el futuro de la investigación antropológica sobre Rapa Nui está derivando en un círculo virtuoso de cooperación entre investigadores/informantes/autores (extranjeros, continentales y de la comunidad rapanui) e instituciones dirigidas por profesionales rapanui. En este contexto dialógico, vemos cómo se posicionan nuevos temas de interés y de urgencia que definen también los planes y los programas de las políticas públicas.

Los artículos presentados en este dossier dan cuenta en su conjunto, de este giro paradigmático de la investigación dialógica y que tiene dobles repercusiones: se plantea desde la generación de conocimiento nuevo y pretende aportar en la comprensión de la realidad contemporánea insular para aplicaciones in situ. Algunos de los autores de los artículos que siguen participaron en el Simposio "Rapa Nui: patrimonio, sociedad y cultura desde una perspectiva contemporánea" del año 2018, anunciado en el inicio de este artículo. Todos ellos nos revelan una apertura conceptual y disciplinar en torno a la contemporaneidad de los asuntos rapanui y recogen problemáticas urgentes para la propia comunidad, así como articulaciones metodológicas para su abordaje. 


\section{Agradecimientos}

Deseamos agradecer por la contribución a las ideas y procesos que este artículo recoge a José Bengoa, Javiera Luco, Paulina Torres y Susana Rochna-Ramírez. De manera muy especial a Riet Delsing por sus siempre enriquecedores comentarios y la revisión del borrador.

\section{Notas}

${ }^{1}$ Usaremos la nomenclatura Rapa Nui para referir a la entidad geográfica y rapanui cuando aludimos a sujetos culturales o al gentilicio.

${ }^{2}$ El seminario se originó por iniciativa de Andrea Seelenfreund, de la Universidad Academia de Humanismo Cristiano, Valentina Fajreldin, de la Facultad de Odontología de la Universidad de Chile, y Riet Delsing, investigadora independiente. Luego se unió Diego Muñoz, del Centro de Investigación y Documentación de Oceanía (CREDO) de Francia. Contó con el patrocinio y la colaboración de las siguientes instituciones isleñas: Corporación Cultural de la Municipalidad de Isla de Pascua, Consejo de Monumentos Nacionales, Corporación de Arte y Cultura Tongariki, Fundación Toki, Secretaría Técnica de Patrimonio Rapa Nui, Centro Cultural Aukara, Museo Antropológico P. Sebastián Englert (MAPSE) y Aguas Vaitea.

${ }^{3}$ Reconozcamos también que la incorporación de la Araucanía y de Rapa Nui se realizó por procedimientos diferentes. El primer territorio fue invadido militarmente, mientras que el segundo fue anexado a través de un tratado con el consejo de jefes local. Para los detalles de la historia véase Bengoa (2004).

${ }^{4}$ Esto, principalmente a través de la Ley 16.441 de 1967 que crea el departamento y la comuna de Isla de Pascua. La isla deja de depender de la Armada y se instalan oficinas de todos los servicios públicos. Esta ley fue discutida en Chile continental sin la participación directa de los rapanui, en coherencia con la falta de voluntad política de la época hacia la participación ciudadana. Sin embargo, el Comité de Adelanto Pascuense, formado por inmigrantes rapanui en el continente con el apoyo del abogado Ismael Parga, logró reunirse con algunos senadores e incidir en algunos aspectos de la formulación de dicha ley (información personal de los autores). Véase una interpretación complementaria en Delsing (2017).

${ }^{5}$ Los trabajos de restauración de los sitios monumentales (Ahu Akivi en 1960) y luego de la aldea de Orongo fueron financiados por el World Monuments Fund. A partir de 1967 el Art. 40 de la Ley 16.441 establecía un gravamen sobre los ingresos del Casino Municipal de Viña. La mitad se destinaba a solventar los gastos de la Municipalidad de la isla y la otra mitad para el estudio y puesta en valor del patrimonio arqueológico. El fondo lo administraba la
También agradecemos a Claudio Espinoza, director de esta revista, por invitarnos al desafío de escribir este artículo. Diego Muñoz contó con financiamiento del Proyecto ERC Starting Grant 803302, "Indigeneities in the 21st Century" dirigido por el profesor Philipp Schorch (LMU, Alemania).

Intendencia de Valparaíso, con base en presupuestos anuales y proyectos. Parte de esos fondos se utilizaron, a fines de los años sesenta, para la restauración del Complejo Ceremonial de Tahai, a cargo de los arqueólogos William Mulloy y Gonzalo Figueroa. El Decreto Ley № 567 de 1974 dejó sin efecto este ensayo. A partir de esa fecha la asignación de fondos públicos a la arqueología quedó supeditada a la necesidad de presentar proyectos a las respectivas instituciones isleñas que tienen injerencia en el tema.

${ }^{6}$ Entre estos, los diarios de la expedición inglesa de 1774 (capitaneada por James Cook), de la expedición francesa de 1786 (dirigida por Jean François Galaup, conde de La Pérouse) y la información producida por la expedición inglesa de 1868 (encabezada por Richard Ashmore Powell, comandante de la nave de guerra Topaze).

7 Entre ellos se incluye un moai de piedra, varias esculturas antropomorfas de piedra y de madera, dos capas de tela de corteza (mahute) pespunteada, una red de pesca, un pendiente de madera de gran tamaño (reimiro) y varios bolsos de fibra vegetal (kete).

${ }^{8}$ Recordemos que entre 1862 y 1863, un tercio de la población de la isla fue secuestrada y transportada al Perú como mano de obra esclava. En 1866, momento en que se inicia la evangelización, promovida y ejecutada por los Sagrados Corazones de Jesús y María (congregación francesa basada en Valparaíso, Tahití y Mangareva), en la isla no vivían más de mil personas (Maude, 1981; McCall, 1976; Muñoz, 2017a). Los informes médicos de la nave O'Higgins señalan las malas condiciones sanitarias de la sociedad y anuncian su inevitable extinción (Bate 1930 [1870]).

${ }^{9} \mathrm{Si}$ bien no existieron otras expediciones científicas sino hasta 1911, cabe señalar que en cada visita de inspección realizada por la Armada chilena hasta los años sesenta se redactaron informes médicos, censos, datos demográficos y descripciones sobre la economía, entre otros, que hoy nos sirven como fuentes. En varios aspectos, los autores de estos informes siguen leyendo la realidad insular desde los conceptos naturalistas, dado que la población es descrita como parte del paisaje y en ellos se anuncia la próxima desaparición de los rapanui o la "raza".

${ }^{10}$ Sin embargo no es el primer diccionario sobre la lengua 
rapanui. Al trabajo de Martínez lo precedió el de Tepano Jaussen (1893) y el léxico de Hippolyte Roussel (1908), ambos actores de la evangelización rapanui.

${ }^{11}$ Su estadía fue entre el 9 de marzo de 1914 y el 18 de agosto de 1915.

${ }^{12}$ Muñoz (2017b, p. 44) escribe: "Recordemos quiénes fueron los informantes de Routledge en 1914. Su colaborador más cercano y quien ofició de intérprete fue Juan Tepano (1872-1947), hijo de Esteban Rano y Paulina Veriamo. Según Routledge era de filiaciones mata Tupahotu y Ure o Hei. Veriamo era la persona más anciana en la isla y recordaba aún algunas ceremonias de iniciación, de matrimonio, así como las epidemias de viruela luego de los raids esclavistas (Routledge, 1919, p. 227). Junto con Veriamo, un selecto grupo de ancianos, nacidos todos antes de las incursiones esclavistas del Perú, permitieron a Routledge reconstruir los restos de la sociedad del pasado: Kapiera Revahiva, Buenaventura Hatirenga, Juan Nuku, Ramón Te Haha, Juan Porotu, Eutimio Rangitopa, loteva Maherenga, Miguel Mutiheo, Nicolás Pakarati, Ramón Hei, María Veri Topatahi y tres ancianos que estaban internos en el leprosario: Arakilio Pua Ara Hoa, Miguel Keremuti y Tomeniko Vaka Tukuonga.

${ }^{13}$ Las notas de campo de Katherine Routledge se encuentran aún inéditas y se conservan en la Royal Geographical Society en Londres. Copias digitales se encuentran en el Pacific Manuscripts Bureau en Canberra, en el Centre de Recherche et Documentation sur l'Océanie en Marsella y en la biblioteca William Mulloy de Rapa Nui (sin embargo, en esta última institución, los DVD se encuentran en muy malas condiciones, lo que hace casi imposible su estudio).

${ }^{14}$ Recordemos las dificultades que tuvo Thompson para hacer hablar al anciano Daniel Ure Vai lko, quien se suponía sabía leer los rongorongo. Según Thompson (1891, p. 515), él no deseaba hablar puesto que dichos objetos eran del tiempo pagano.

${ }^{15}$ El término maori es de origen protopolinésico y se reconstruye como "*ma(q)aoli" o como "*maqoli" y significa verdadero, genuino, real (POLLEX: https://pollex.shh.mpg.de/entry/maqoli/). En el idioma rapanui, según el misionero Roussel (1908, pp. 196, 199, 201, 2011, 236), quiere decir diligente, erudito, hábil, ingenioso, con experiencia, con renombre. Fuentes (1960) agrega los significados de inteligente, sabio, maestro.

${ }^{16}$ Alfred Métraux en ese entonces era reconocido como un prominente antropólogo americanista, con estudios sobre las poblaciones indígenas de Argentina y Paraguay (Laurière, 2014).

${ }^{17}$ Esta era la hipótesis del difusionista Guillaume de Hereszy, quien se basaba en una simple analogía de símbolos entre las tabletas de arcilla de la cultura Mohenjo-Daro y el repertorio de símbolos rongorongo establecido por Tapano Jaussen (Laurière, 2014).

${ }^{18}$ A través del Decreto № 103 del 16 de enero de 1935 del Ministerio de Tierras y Colonización. (https://www.conaf.cl/parques/ parque-nacional-rapa-nui/, consulta 10.11.2020).

${ }^{19}$ A través del Decreto № 4.536 del 23 de julio de 1935 del Ministerio de Tierras y Colonización. En abril de 1966, mediante el DS № 148 del Ministerio de Agricultura, se crea el Parque Nacional de Turismo Isla de Pascua, el cual fue modificado una vez más por el DS № 285 del 3 de junio de 1966. (https://www.conaf.cl/parques/ parque-nacional-rapa-nui/, consulta 10.11.2020).

${ }^{20}$ El noruego Thor Heyerdahl (1952) afirmó que los primeros pobladores de las islas del Pacífico provenían de América, en marcado contraste con la tradición científica establecida. En un intento por encontrar pruebas arqueológicas de los contactos sudamericanos, Heyerdahl organizó y dirigió la Expedición Arqueológica Noruega a la Isla de Pascua y el Pacífico oriental en 1955-1956. La expedición estuvo conformada por Heyerdahl, además de un arqueólogo noruego y tres arqueólogos norteamericanos, de formación americanista (William Mulloy, Edwin Ferdon y Carlyle Smith). Permanecieron varios meses en la isla realizando trabajos en diferentes sitios emblemáticos de esta. Como exigencia impuesta por el gobierno chileno, se integraron dos jóvenes estudiantes del Centro de Estudios Antropológicos de la Universidad de Chile, Gonzalo Figueroa GarcíaHuidobro y Eduardo Sánchez. Esta expedición tuvo varios impactos importantes en el desarrollo de la arqueología en la isla.

${ }^{21}$ Traducción nuestra.

${ }^{22}$ El tema de la aculturación, según lo planteado por Herskovits (1938), es recogido recién en los años setenta por la antropología chilena. Fue una lectura básica de los programas de antropología en Chile desde esa década hasta al menos entrado el siglo XXI.

${ }^{23}$ Traducción nuestra.

${ }^{24}$ Este Centro de Estudios en sus inicios acogió tanto a los antropólogos Claudio Cristino, Patricia Vargas y Lilian González, estudiantes del Departamento de Antropología, como a los académicos Gastón Cea y César Aguilera del proyecto "Mata Ki Te Rangi" de la Escuela de Diseño de la Universidad de Chile. El Centro quedó vinculado por muchos años a la Facultad de Arquitectura de esta universidad, dado que se creó a instancias de su decano, Gastón Etcheverry, quien abogaba por un centro de investigación inter y transdisciplinar.

${ }^{25}$ La Unión de Valparaíso, 1 de febrero de 1956. Agradecemos al colega Rolf Foerster por esta información.

${ }^{26} \mathrm{https} / / / w w w . m h n c o n c e p c i o n . g o b . c 1 / 640 / w 3-p r o p e r t y v a l u e-42733$. html?_noredirect=1 (consulta 02.11.2020).

${ }^{27}$ Los proyectos de restauración de los Ahu Nau Nau (1978) y Ahu Tautira (1979) fueron dirigidos por Sergio Rapu. El primero contó con la participación de las estudiantes de arqueología y antropología Sonia Haoa y Verónica Cuadra, respectivamente. En las excavaciones de Ahu Tautira participaron el arqueólogo norteamericano Charles Love y la entonces estudiante de arqueología Andrea Seelenfreund.

${ }^{28}$ Investigación realizada en 1981, dirigida por George Gill (Universidad de Wyoming) en colaboración con Sergio Rapu. Los arqueólogos en terreno fueron Leslie Shaw (Universidad de Wyoming) y Andrea Seelenfreund (por parte del Museo).

${ }^{29}$ Entre 2001 y 2020 se defendieron cuatro tesis de posgrado en universidades extranjeras de antropólogos extranjeros (Santa Coloma, 2001; Bendrups, 2006; Andreassen, 2008; Young, 2011).

${ }^{30}$ Petero Edmunds Paoa asume con posterioridad la alcaldía de la Municipalidad de Rapa Nui por varios períodos: 1994-1996, 1996-2000, 2000-2004, 2004-2008, 2012-2016, 2016-2020. En 2010 
fue además gobernador.

${ }^{31}$ Alberto Hotus Chávez fue alcalde entre 1992 y 1994 , y concejal de la comuna entre 1996 y 2016. Desde 1979 hasta 2018 fue el presidente del Consejo de Ancianos.

${ }^{32}$ En comunicación personal con los autores (9 de noviembre de 2020).

${ }^{33}$ El libro de Rochna-Ramírez (1996), escrito en 1993 a petición de la Comisión Especial de Pueblos Indígenas (CEPI) y publicado por la CONADI, fue citado en distintas sesiones parlamentarias al momento de discutirse las modificaciones a la Ley Indígenas 19.253 para integrar las demandas rapanui (Biblioteca Nacional del Congreso, 1998).

${ }^{34}$ Comunicación personal de los autores con el académico José Bengoa, quien participó en calidad de asesor en dicho proceso (30 de octubre de 2020).

${ }^{35}$ En efecto, la Ley 19.253 fue modificada en 1997 a través de la Ley 12.587, que estableció que para definir la pertenencia a la "etnia rapanui" se aplicarían solo las letras a y b del Artículo 2 de la ley 19.253, y no la letra c, que extendía la adquisición de la calidad indígena a los cónyuges de personas indígenas. Esta modificación permitió, en estricto rigor, que solo las personas rapanui, esto es, los descendientes de otro rapanui, pudiesen adquirir tierras en la isla. También se definió la composición de la Comisión de Desarrollo de Isla de Pascua (CODEIPA), institución única en la política nacional indígena toda vez que entre sus competencias está evaluar y proponer planes de desarrollo para el territorio insular, así como determinar las necesidades de tierras para los rapanui. Esta comisión cuenta con cinco miembros elegidos por los rapanui, más el presidente del Consejo de Ancianos y los jefes de los(as) representantes ministeriales en la isla, el alcalde y el gobernador.

${ }^{36}$ Los arqueólogos J. M. Ramírez y M. Rauch en la CONAF; en el Museo: C. Cristino, C. Gómez y luego F. Torres; en la oficina del Ministerio de Bienes Nacionales la socióloga J. Ramírez; en la CONADI, el antropólogo social T. Gutiérrez; en la Municipalidad, el antropólogo y sociólogo J. Adán.

${ }^{37}$ El proceso tiene tres aristas: 1) desde 1986 todos los gobernadores han sido rapanui así como también todos los alcaldes;

\section{Referencias bibliográficas}

Alarcón, A. (2008). Pua A Rahoa: La historia de la migración del primer rey Hotu Matu'a. Santiago: Pehuén.

Alvear, A. (2014). Isla de Pascua: ¿Voracidad o resistencia alimentaria?(Tesis inédita de pregrado en antropología). Universidad de Chile, Chile.

Andreassen, O.I. (2008). When home is the navel of the world: An ethnography of young Rapa Nui between home and away. (Tesis inédita de doctorado). University of New South Wales, Sydney.

Andrade, P. (2004). Artífices del imaginario: la puesta en escena, una aproximación a la construcción de identidad Rapa Nui. (Tesis inédita de licenciatura en antropología). Universidad Academia de
2) la creación de la CODEIPA como organismo netamente local y 3 ) la presencia de los rapanui en los servicios públicos en diferentes grados jerárquicos.

${ }^{38}$ A través de este trabajo de mediación, la propia comunidad comenzó a definir los perfiles de turismo y las zonas excluidas de los circuitos. Aparecieron los primeros mapas turísticos del tipo "guía". Varios de los miembros de esta mesa directiva se convirtieron en personalidades relevantes tanto en la economía como en la política local (comunicación de los autores con Javiera Luco, octubre de 2020).

${ }^{39}$ El patrimonio cultural inmaterial o "patrimonio vivo", según la definición proporcionada por la UNESCO, se refiere a las prácticas, expresiones, saberes o técnicas transmitidas por las comunidades de generación en generación. (https://es.unesco.org/themes/patrimoniocultural-inmaterial, consulta 02.11.2020).

${ }^{40}$ Por ejemplo, la licitación pública № 1725-110-LE11 para la elaboración del Estudio de Desarrollo del Patrimonio Cultural de Rapa Nui (Consejo Nacional de la Cultura y las Artes, 2012). El énfasis estuvo puesto en el patrimonio inmaterial y fue trabajado por un conjunto de especialistas interdisciplinares -arqueólogos, antropólogos sociales, sociólogos, arquitectos y especialistas de la comunidad-.

${ }^{41}$ Comunicación personal de los autores con Paulina Torres (octubre de 2020).

${ }^{42}$ Comunicación personal de los autores con Paulina Torres (octubre de 2020).

${ }^{43} \mathrm{El}$ mana es un concepto transpolinésico que refiere a lo sagrado como una fuerza total. En la Polinesia occidental no se refiere solamente a una sustancia, una energía invisible y espiritual en sí, sino a una potencia que se evidencia en los resultados de una acción (Keesing, 1984). En la Polinesia oriental está relacionado con el poder espiritual del jefe y su poder fecundador, siendo el mana el medio invisible que conecta al jefe con la divinidad y los antepasados. Por esta razón, la figura del jefe está rodeada de una serie de prohibiciones, en especial su cabeza, la cual es considerada tapu, prohibido por su sacralidad (Métraux, 1971 [1941]).

${ }^{44}$ Gentilicio para los habitantes del archipiélago de las Tuamotu.

Humanismo Cristiano, Santiago.

Andueza, P. (2000). Hacia el reconocimiento de los derechos políticos de los pueblos originarios: El modelo de cogestión en Isla de Pascua. Estudios Atacameños, 19, 113-120. doi: https://doi. org/10.22199/S07181043.2000.0019.00006.

Arias, M. (2011). Frecuencia y expresión de la tolerancia e intolerancia a la lactosa en población de la Isla de Pascua, Chile. (Tesis inédita de titulación en antropología). Universidad de Chile, Santiago.

Arnold, M. (1990). La antropología social en Chile: Producciones y representaciones. Sin datos editoriales. Recuperado de http:// 
repositorio.uchile.cl/bitstream/handle/2250/122304/Arnold\%20 L001\%201990.pdf?sequence=1 (Consulta 16.09.2020).

Arredondo, A. M. (2000a). The view of woman in Rapanui society: Part 1. Women in myths and legends. Rapanui Journal, 14(2), 42-46. (2000b). The view of woman in Rapanui society: Part 2:

Rapanui women as seen through the eyes of seafarers, missionaries and scientists in the eighteenth century. Rapanui Journal, 14(3), 80-84.

Arriagada, J. (2015). Representación visual de los rapanui entre 1888 y 1970. (Tesis inédita de titulación en antropología). Universidad Academia de Humanismo Cristiano, Santiago.

Arthur, J. (2012). Now they say the land is not ours: On Rapanui worldviews and land-being relations. (Tesis inédita de magíster). Universidad de California, Los Ángeles.

(2015). Reclaiming mana repatriation in Rapa Nui. (Tesis inédita de doctorado). Universidad de California, Los Ángeles.

(2018). Repatriación indígena en el Museo Rapa Nui.

Colecciones Digitales, Subdirección de Investigación, Servicio Nacional del Patrimonio Cultural. Recuperado de https://www. museorapanui.gob.cl/679/articles-90210_archivo_PDF.pdf (consulta 13.11.2020)

(2020). Repatriation in Rapa Nui, Ka Haka Hoki Mai Te Mana Tupuna. En Forde, C., McKeown, T. \& Keeler, H. (Eds.), The Routledge companion to indigenous repatriation: Return, reconcile, renew (pp. 220-237). Oxon, New York: Routledge.

Astete Paoa, T. (2014). Re'o Tupuna. (Tesis inédita de titulación en arqueología). Universidad Sek, Santiago.

Atam, M. (2012). Desde el mito a la evidencia arqueológica: Análisis de micro restos vegetales adheridos en artefactos de obsidiana: Contexto arqueológico en Rapa Nui. (Tesis inédita de titulación en arqueología). Universidad Sek, Santiago.

Bahamóndez, M. (2000), Isla de Pascua, conservación de su estatuaria: un proceso en desarrollo. Conserva, 4, 57-70.

Barthel, T. S. (1965). Native documents from Easter Island: Reports of the Norwegian Archaeological Expedition to Easter Island and the East Pacific. En Heyerdahl, T. \& Ferdon, E. (Eds.), Miscellaneous papers, Vol. 2. (pp. 387-390). Estocolmo: Monographs of the School of American Research and the Kon-Tiki Museum.

(1978). The eighth land: The Polynesian discovery and settlement of Easter Island. Honolulu: The University Press of Hawai'i.

Bate, T. (1930 [1870]. Descripción de la Isla de Pascua. Revista de Marina, 5, 490-500.

Bateson, G. (1972). Steps to an ecology of mind: Collected essays in anthropology, psychiatry, evolution, and epistemology. Chicago: University of Chicago Press.

Bendrups, D. (2006). Continuity in adaptation: A history of Rapanui music. (Tesis inédita de doctorado). Macquarie University, Sydney.

Bengoa, J. (Comp.) (2004). La memoria olvidada: Historia de los pueblos indígenas de Chile. Compilación del Informe de la Comisión de Verdad Histórica y Nuevo Trato. Santiago: Cuadernos del Bicentenario.

(2014). La trayectoria de la antropología en Chile. Antropologías del Sur, 1(1), 15-42.
Berenguer, P. (2018). Estudio del uso y consumo de especies vegetales durante el poblamiento temprano de Rapa Nui, a través del análisis de almidones adheridos a artefactos líticos pertenecientes al sitio Anakena. (Tesis inédita de titulación en arqueología). Universidad Sek, Santiago.

Bierbach, A. \& Cain, H. (1996). Religion and language of Easter Island: An ethnolinguistic analysis of religious key words of Rapa Nui in their Austronesian context. Baessler-Archiv, Beiträge zur Völkerkunde, Neue Folge Beiheft 9. Berlin: Dietrich Reimer Verlag.

BNC (Biblioteca de Congreso Nacional). (1998). Historia de le ley 19.587: Modifica los artículos 67 y 69 de la Ley 19.253 de protección, fomento y desarrollo de los pueblos indígenas, respecto a la constitución del dominio en la Isla de Pascua para los miembros de la comunidad Rapa Nui. Recuperado de www.bcn.cl/historiadelaley. (Consulta 09/08/2018).

Bórmida, M. (1951). Somatología de la Isla de Pascua. RUNA, 4(1-2), 178-222.

Buck, P. (1938). Vikings of the sunrise. Nueva York: Frederick A. Stokes Company.

Budinich, B. (2006). Desafíos de la nueva museología: el caso del MAPSE y de su relación con la comunidad Rapa Nui en Isla de Pascua. (Tesis inédita de titulación en antropología). Universidad Academia de Humanismo Cristiano, Santiago.

Cain, H. (1979). Aitu: Eine Untersuchung zur autochthonen Religion der Samoaner. Arbeiten aus dem Seminar Völkerkunde der Johann Wolfgang Goethe-Universität Frankfurt am Main, Band 10. Wiesbaden: Franz Steiner Verlag.

Campbell, R. (1971). La herencia musical de Rapa Nui: Etnomusicología de la Isla de Pascua. Santiago: Andrés Bello. (1993). Rapanui's ancient medicinal arts. En Fischer, S. R. (Ed.), Easter Island studies (pp. 158-162). Londres: Oxbow Monograph 32.

Castro, N. (1996). Misioneros y milenaristas: Isla de Pascua, 1864-1914. (Tesis inédita de licenciatura en historia). Universidad de Valparaíso, Valparaíso.

Cervellino, M. (1993). Investigación arqueológica en la caverna Ana Kai Tangata: Isla de Pascua. Rapa Nui Journal, 7(3), 52-54.

Charó, C. (2014). Acerca del poblamiento inicial de Rapa Nui: Una mirada desde los almidones adheridos a artefactos líticos. (Tesis inédita de titulación en arqueología). Universidad de Chile, Santiago.

Consejo Nacional de la Cultura y las Artes (2012). Estudio diagnóstico del desarrollo cultural del pueblo Rapanui. Sección Observatorio Cultural. Recuperado de www.cultura.gob.cl/estudios/ observatorio-cultural (Consulta 10/11/2020).

Cristino, C. (1979). Isla de Pascua: proposición de una estrategia metodológica para el estudio de patrones de asentamiento. (Tesis inédita de titulación en arqueología). Universidad de Chile, Santiago.

Cristino, C., Recasens, A., Vargas, P., González, L. \& Edward, E. (1984). Isla de Pascua: Procesos, alcances y efectos de la aculturación. Santiago: Facultad de Arquitectura y Urbanismo, Instituto de Estudios Isla de Pascua, Universidad de Chile.

Cuadra, V. (1979). Te pito o te henua: Estudio antropológico de 
la comunidad de pescadores desde el siglo XVIII hasta el presente, tomando como muestra la caleta de Hanga Roa. (Tesis inédita de licenciatura en antropología). Universidad de Concepción, Concepción.

De Estella, B. (1920). Los misterios de la Isla de Pascua. Santiago: Imprenta Cervantes.

(1921). Mis viajes a Pascua. Santiago: Imprenta Cervantes.

Delaire, N. (2005). La escritura del otro en los navegantes, ilustrados y misioneros en la Polinesia del Siglo XVIII y XIX. (Tesis inédita de licenciatura en historia). Universidad de Valparaíso, Valparaíso.

Delsing, R. (2009). Articulating Rapa Nui: Polynesian cultural politics in a Latin American nation-state. (Tesis inédita doctoral). Santa Cruz: Universidad de California, Santa Cruz.

(2015). Articulating Rapa Nui: Polynesian cultural politics in a Latin American nation-state. Honolulu: University of Hawai'i Press. (2017). Articulando Rapa Nui: Políticas culturales polinésicas frente al Estado chileno. Santiago: LOM.

Dides, C., Pérez, S., Fajreldin, V., Soto, M. \& González, G. (2005). Salud, sexualidad y reproducción: Sistematización de investigaciones y experiencias en pueblos indígenas en Chile, 1990-2004. Santiago: Corporación de Salud y Políticas Sociales (CORSAPS).

Drapkin, I. (1935). Contribución al estudio antropológico y demográfico de los pascuenses. Journal de la Société des Américanistes de Paris, (27), 256-302.

Edwards, R. (1918). La Isla de Pascua: Consideraciones expuestas acerca de ella por Mons. Rafael Edwards Obispo y vicario castrense, que la visitó en julio de 1916 y junio de 1917. Santiago: Imprenta de San José.

Englert, S. (1948). La tierra de Hotu Matu'a: Historia, etnología y lengua de la Isla de Pascua. Padre Las Casas: Imprenta San Francisco.

(2006 [1936]). Leyendas de Isla de Pascua. Isla de Pascua: Rapanui Press.

Escobar, B \& Lagos, X. (2009). Voces del Pacífico: Una comunidad en busca del reconocimiento autonómico. (Tesis inédita de titulación en arqueología). Universidad Academia de Humanismo Cristiano, Santiago.

Faba, P. (2012). Entre le continent et l'île : Dimensions de la patrimonialisation de Rapa Nui (île de Pâques), Chili. (Tesis inédita de doctorado en historia del arte). Université Paris I, PanthéonSorbonne, París.

Fabian, J. (2002). Time and the other: How anthropology makes its object. Nueva York: Columbia University Press.

Fajreldin, V. (2002). La medicina herbolaria en Isla de Pascua: Acercamiento antropológico a la cultura médica contemporánea en Rapanui. (Tesis inédita de titulación en antropología). Universidad de Chile, Santiago.

(2012). Vulnerabilidad y esperanza en torno al patrimonio cultural en Rapa Nui: Perspectiva antropológica. Observatorio Cultural del Consejo Nacional de la Cultura y las Artes [en línea], (15), 8-20.

(Ed.) (2017). Colección cultura y patrimonio inmaterial de Rapa Nui, 3 vols. Santiago: Ocho Libros.
(2020). Culture, power and public policy: The trajectory of traditional medicine on Easter Island in the last decade. En Vogt, B., Kühlem, A., Mieth, A., Bork, H.-R. (Eds.), Easter Island and the Pacific: Cultural and environmental dynamics (pp. 63-70). Santiago: Rapanui Press.

Ferdon, E. (1957). Notes on the present-day Easter islanders. Southwestern Journal of Anthropology, 13(3), 223-238.

(1958). Easter Island exchange systems. Southwestern Journal of Anthropology, 14(2), 136-151.

Figueroa, G. \& Sánchez, E. (1965). Adzes from certain islands of eastern Polynesia. En Heyerdahl, T. \& Ferdon, E. N. (Eds.), Reports of the Norwegian archaeological expedition to Easter Island and the East Pacific, Vol. 2 (pp. 169-201). Miscellaneous Papers. Santa Fe: School of American Research, Kon Tiki Museum.

Fischer, S. R. (1997). Rongorongo: The Easter Island script: History, traditions, texts. Oxford: Clarendon Press.

(2009). The Métraux-Barthel correspondence (1956-61) and the Métraux field-notes of Easter Island, Parte II. Rapa Nui Journal, 23(1), 55-66.

Foerster, R. (2015). Rapa Nui: El colonialismo republicano chileno cuestionado (1902-1905). Santiago: Catalonia.

(2016). Política, escuela y memoria: Una aproximación contemporánea a Rapa Nui. Historia, 49(1), 237-259.

Foerster, R. \& Montecino, S. (2018). Rapa Nui: La sociedad de amigos de Isla de Pascua: Documentos de una impugnación nacionalista (1946-1953). Santiago: Catalonia.

Fuentes, J. (1960). Diccionario y gramática de la lengua de la Isla de Pascua. Santiago: Andrés Bello.

Garretón, M. A. (2005). Social sciences and society in Chile: institutionalization, breakdown and rebirth. Social Science Information, 44(2-3), 359-409.

Garrote, J. I. (2013). Habitando la escuela: Educación y transculturación en Rapa Nui, 1914-1965. (Tesis inédita de titulación en antropología). Universidad de Chile, Santiago.

Gill, G. W. (2000). Investigation of the 1981 Easter Island anthropological expedition. En Stevenson, C. y Ayres, S. W. (Eds.), Easter Island archaeology: Research on early Rapanui culture (pp. 5558). Los Osos (California): Easter Island Foundation, Bearsville Press.

Gill, G. W. \& Owsley, D. W. (1993). Human osteology on Rapa Nui. En Fischer, S. R. (Ed.), Easter Island studies (pp. 56-72). Oxford: Oxbow Monograph 32,.

González, L. (1984). Isla de Pascua: problemática educacional. (Tesis inédita para optar al título de antropólogo). Universidad de Chile, Santiago.

González, J. (2017). Umu Atua: Umana Haka Kaina: Las paradojas del don y contra don en los umu atua Rapa Nui. (Tesis inédita de titulación en antropología). Universidad Academia de Humanismo Cristiano, Santiago.

Goñi, A. (1983). El migrante pascuense en el continente: 19681971. En Arqueología y ciencia, Primeras jornadas. Santiago: Museo Nacional de Historia Natural.

Green, R. C. (1998). Rapanui origins prior to European contact: 
The view from Eastern Polynesia. En Vargas, P. (Ed.), II International Congress on Easter Island \& East Polynesian Archaeology (pp. 87110). Santiago: IEIP, FAU, Universidad de Chile.

(2000). Origins for the Rapanui of Easter Island before European contact: Solutions from holistic anthropology to an issue no longer much of a mystery. Rapa Nui Journal, 14(3), 71-76.

Gregory, H. E. (Ed.) (1921). Proceedings of the first Pan-Pacific Scientific Congress. Bernice P. Bishop Museum Special Publication, (7), Honolulu.

Grifferos, A. (1997). La otra cara del Paraíso: Comunidad, tradición y colonialismo en Rapanui, 1864-1964. (Tesis inédita de licenciatura en historia). Universidad de Valparaíso, Valparaíso.

Handy, E. S. (1930). The problem of Polynesian origins. Bernice P. Bishop Museum Occassional Papers, (9), 1-27.

Haoa, V. (2009). Te Puka Natura Rapanui. Autoedición con el apoyo de Umanga Hatu Reo (Academia de la Lengua Rapanui), CONADI, Municipalidad de Isla de Pascua y Colegio Lorenzo Baeza. (2017). Estado de situación de la educación y la lengua en Rapa Nui. En Fajreldin, V. (Ed.). En Colección cultura y patrimonio inmaterial de Rapa Nui, vol. 2. (pp. 17-30). Santiago: Ocho Libros.

Haoa, F. (2010). 122 años, 122 imágenes. Valparaíso: Proyecto Bicentenario, Fondo de Cultura del Gobierno Regional de Valparaíso.

Herskovits, M. J. (1938). Acculturation: The study of culture contact. Nueva York: J. J. Augustin.

Heyerdahl, T. (1952). American indians in the Pacific: The theory behind the Kon-Tiki Expedition. Londres: Allen \& Unwin.

Horley, P. (2005). Allographic variations and statistical analysis of the rongorongo script. Rapa Nui Journal, 19 (2), 107-116. (2007). Structural analysis of rongorongo inscriptions.

Rapa Nui Journal, 21(1), 25-32.

Horley, P. \& López, L. (2014). A new manuscript of Pua Ara Hoa 'a Rapu from the archives of William Mulloy, Part 1: Description of the manuscript. Rapa Nui Journal, 28 (2), 35-48.

Hotus, A. \& Consejo de Jefes Rapanui (1988). Te Mau Hatu o Rapa Nui: los soberanos de Rapa Nui, pasado, presente y futuro. Santiago: Emisión.

Howard, A. (1967). Polynesian origins and migrations. En Highland, G. A. (Ed.), Polynesian culture history (pp. 45-101). Bernice P. Bishop Mus. Spec. Publ. 56. Honolulu: Bishop Museum Press.

Huke, P. (2011). Colonialismo en Isla de Pascua, 1897-1966: Un acercamiento etnográfico. Santiago: Universidad Bolivariana.

Jaussen, T. (1893). L'île de Pâques : Historique et écriture. Bulletin de Géographie Historique, (2), 240-270.

Keesing, R. M. (1984). Rethinking "mana". Journal of Anthropological Research, 40(1), 137-156.

Kirch, P. (2010). Peopling of the Pacific: A holistic anthropological perspective. Annual Review of Anthropology, (39), 131-148.

Knoche, W. (1912a). Die Lepra auf der Osterinsel. Zeitschrift für physikalische und diätische Therapie, 1. Berlín: G. Thieme. (1912b). Tres notas sobre la Isla de Pascua. Revista Chilena de Historia y Geografía, (2), 442-466.

(1913). Der Lepraherd auf der Osterinsel. Medizinische
Klinik, 1(5), 13.

(1926-1927). Waren die Toromiro der Osterinsel Marionetten? Zeitschrift für Ethnologie, (58/59), 95-98, Berlín. Recuperado de https:// www.digi-hub.de/viewer/image/1568386613587/549/LOG_0191/.

Larraín, J. (2001). La identidad chilena. Santiago: LOM.

Latcham, R. (1936). Boletín del Museo Nacional, Tomo 15, 190.

Laurière, C. (2014). L'odyssée pascuane: Mission MétrauxLavachery, Île de Pâques (1934-1935). París: Les Carnets de Bérose, Collège de France.

Lavachery, H. (1939). Les pétroglyphes de l'île de Pâques. Antwerpen: De Sikel.

Lenz, R. (1905). Diccionario etimológico de las voces chilenas derivadas de las lenguas indígenas americanas. Santiago: Universidad de Chile.

(1924). Estudio sobre los indios de Chile. Publicaciones del Museo de Etnología y Antropología de Chile, 4(1-2), 147-160.

Leyton, D. (2004). Hacia una antropología del cuerpo: Significación cultural de los cuidados corporales en mujeres Rapa Nui. (Tesis inédita de titulación en antropología). Universidad de Chile, Santiago.

Linton, R. (1945). Cultura y personalidad. México: Fondo de Cultura Económica.

Mardones, A. (2016). Vistiendo las transformaciones culturales: una transformación a la utilización y significación del textil en Rapa Nui desde los primeros contactos hasta el período de cristianización y colonización temprana. (Tesis inédita de titulación en antropología). Universidad Academia de Humanismo Cristiano, Santiago.

Martínez, E. (1913). Vocabulario de la lengua rapa-nui, Isla de Pascua. Santiago: Instituto Central Meteorológico y Geofísico de Chile.

Matisoo-Smith, E. \& Robins, J. H. (2004). Origins and dispersals of Pacific peoples: Evidence from mdDNA phylogenies of the Pacific rat. Proceedings of the National Academy of Science, 101(24), 9167-9172.

Maude, H. E. (1981). Slavers in Paradise: Peruvian slave trade in Polynesia, 1862-1864. Stanford: Standford University Press.

McCall, G. (1976). Reaction to disaster: Continuity and change in Rapanui social organization. (Tesis inédita de doctorado). Australian National University, Canberra.

(1981). Rapanui: Tradition and survival on Easter Island. Honolulu: University of Hawai'i Press.

McMillan-Brown, J. (1997 [1924]). The riddle of the Pacific. Boston: Small Maynard and Co.

Melka, T. S. \& Schoch, R. M. (2020). Exploring a mysterious tablet from Easter Island: The issues of authenticity and falsifiability in rongorongo studies. Cryptologia. doi: 10.1080/01611194.2019.1706065.

Menares, A. (2004). Políticas públicas para los pueblos indígenas en Chile: Los desafíos del desarrollo con identidad: Una mirada al Fondo de Desarrollo Indígena de CONADI. (Tesis inédita de titulación en antropología). Universidad de Chile, Santiago.

Métraux, A. (1957). Easter Island: A stone age civilization in the Pacific. Nueva York: Oxford University Press.

(1971 [1941]). Ethnology of Easter Island. B.P. Bishop

Museum Bulletin 160. Honolulu: Bishop Museum Press.

Ministerio de Relaciones Exteriores (1935). Isla De Pascua: 
Antecedentes relativos a la visita de la Comisión Científica FrancoBelga para realizar estudios arqueológicos. Visita Comisión Científica Franco Belga Correspondencia. Archivo Nacional, ARNAD-COMREL-V3644.

Moore, E. (1910). Informe del Museo Nacional. Boletín del Museo Nacional, Tomo 1(1), 4-13.

Mora, H. (2016). La institucionalización de las ciencias antropológicas en Chile: Una aproximación a las dinámicas socioorganizativas y cognoscitivas en la conformación del espacio científico (1860 y 1954). (Tesis inédita de doctorado en ciencias sociales). Facultad de Humanidades y Ciencias de la Educación, Universidad Nacional de La Plata, La Plata.

Moreno Pakarati, C. (2011a). El poder político nativo en Rapa Nui tras la muerte de los últimos "Ariki Mau". En Fuentes, F. \& Cristino, C. (Eds.), La Compañía Explotadora de Isla de Pascua: Patrimonio, memoria e identidad en Rapanui (pp. 53-74). Concepción: Escaparate. (2011b). Rebelión, sumisión y mediación en Rapanui (1898-1915). En Fuentes, F. \& Cristino, C. (Eds.), La Compañía Explotadora de Isla de Pascua: Patrimonio, memoria e identidad en Rapanui (pp. 75-90). Concepción: Escaparate.

(2013). La importancia de la arqueología histórica en Rapa Nui: El caso de la explotación ovejera y la domesticación del poder colonial. En Fuentes, M. (Ed.), Rapa Nui y la Compañía Explotadora (pp. 284-293). Rapa Nui: Rapanui Press.

Mückler, H. (2015). Der vergessene Osterinsel-Forscher Walter Knoche, wissenschaftlicher Leiter der chilenischen Rapa NuiExpedition 1911. En Denzel, M.A., Dharampal-Frick, G., Gründer, H., Häberlein, M., Hiery, H., Koschorke, K., Meier, J., Mückler, H., Pietschmann, H., Schnurmann, C. \& Zeuske, M. (Eds.), Jahrbuch für Europäische Überseegeschichte (pp.123-146). Gesellschaft für Überseegeschichte und der Forschungsstiftung für Europäische Überseegeschichte, Wiesbaden: Harrassowitz Verlag.

Munizaga, C. (1961). Estructuras transicionales en la migración de los araucanos de hoy a la ciudad de Santiago de Chile. Santiago: Editorial Universitaria.

Muñoz, D. (2007). Rapanui translocales: configuración de la etnicidad rapanui en Santiago de Chile. (Tesis inédita de titulación en antropología). Universidad Academia de Humanismo Cristiano, Santiago.

(2010). Au-delà de l'île de Pâques: De l'insularité et des flux dans l'identité rapanui contemporaine. (Memoria inédita de maestría en etnología y antropología social). EHESS, París.

(2017a). Diaspora Rapanui (1871-2015): L'île de Pâques, le Chili continental et la Polynésie française: Une ethnographie historique de la mobilité dans une société transnationale. (Tesis inédita doctoral en antropología social y etnología). EHESS-CREDO, Marsella.

(2017b). Memorias genealógicas de Rapa Nui: Conexiones pasadas, presentes y futuras. En Fajreldin, V. (Ed.), Historia, espacialidad y territorio en Rapanui, Vol. 1 (pp. 43-70). Santiago: Ocho Libros.

Nahoe, S. (2017). Uso y valoración de la arqueología desde la perspectiva de la comunidad rapanui contemporánea. En Fajreldin,
V. (Ed.), Colección cultura y patrimonio inmaterial de Rapa Nui, Vol. 1 (pp. 71-88). Santiago: Ocho Libros.

Ossandón, V. (1903). Viaje de la corbeta Jeneral Baquedano. Revista de Marina, 34(202), 485-496.

Pakarati, F. (2011). Destruyendo mitos en torno a la Williamson \& Balfour. En Fuentes F. \& C. Cristino (Eds.), La Compañía Explotadora de Isla de Pascua: Patrimonio, memoria e identidad en Rapanui (pp. 287-300). Concepción: Escaparate.

(2016). Costumbres y vivencias en Rapa Nui: He Ako 'e he Noho Ina 'i Rapa Nui. Rapa Nui: Rapanui Press.

Pakarati, F., Paoa, R. \& Madariaga, C. (2018). Te 'Umu ‘i Rapa Nui: La cocción de alimentos en hornos subterráneos en Rapa Nui. Rapa Nui: Autoedición.

Palestini, S., Ramos, C. \& Canales A. (2010). La producción de conocimiento antropológico social en Chile postransición: Discontinuidades del pasado y debilidades presente. Estudios Atacameños, (39), 101-120.

Pate, M., Tuki, F., Hucke, L., Tepano, F., Tepano, C., Pakomio, T., Tuki, E., Pakarati, F., Chávez, A., Hucke, B. \& Haoa, V. (1986). 'A'Amu o Rapa Nui: Relatos de la Isla de Pascua. Valparaíso: Intendencia de Valparaíso, Andrés Bello.

Phillipi, R. A. (1874). Jeografía de la Isla de Pascua y sus habitantes. Santiago: Imprenta Nacional.

Polakowsky, H. (1895). Die Zustände auf der Osterinsel. Globus, (68), 142-144.

Porteous, D. (1981). The modernization of Easter Island. Western Geographical Series, Vol. 19. Victoria: University of Victoria.

Porter, C. (1909). Estado actual de las ciencias antropológicas en Chile. Revista Chilena de Historia Natural, 13(1), 110-122.

Pozdniakov, K. (1996). Les bases du déchiffrement de l'écriture de l'île de Pâques. Journal de la Société des Océanistes, (103), 289-303. doi: 10.3406/jso.1996.1995.

Pozdniakov, I. \& Pozdniakov, K. (2007). Rapanui writing and the Rapanui language: Preliminary results of a statistical analysis. Forum for Anthropology and Culture, (3), 3-36.

Ramírez, F. (2010). El cambio alimentario en Rapa Nui: Usos, desusos y significados asociados a los alimentos en sus procesos de producción, distribución, preparación y consumo. (Tesis inédita para de titulación en antropología). Universidad Academia de Humanismo Cristiano, Santiago.

Ramírez, J. M. \& Hotus, J. (2017). El manuscrito de Pua Ara Hoa: Materiales bilingües para la recuperación de la memoria y la lengua rapanui. Viña del Mar: Rapanui Press.

Rapu, A. (2017). Sexualidad, ciclos vitales y cultura rapanui en el contexto de la globalización. En Fajreldin, V. (Ed.), Colección cultura y patrimonio inmaterial de Rapa Nui, Vol. 3 (pp. 143-154). Santiago: Ocho Libros.

Rapu, R. (2017). Rima o te Rapanui: Polinésicos en el centro sur de Chile. (Tesis inédita de titulación en arqueología). Universidad Sek, Santiago.

Rivas, A. (2017). Ono Tupuna, the richness of the ancestors: Multiples landscapes relationalities in contemporary indigenous Rapa 
Nui. (Tesis inédita de doctorado). Universidad de California, Berkeley.

Rochna-Ramírez, S. (1992). The impact of capitalism on Easter Island: A comparison with other indigenous realities in the Americas. (Tesis inédita de magíster). Universidad de Regina, Regina. (1996). La propiedad de la tierra en Rapa Nui. Santiago: Corporación Nacional de Desarrollo Indígena.

Rojas, R. (2014). El Maíka y la sociedad Rapanui: Estudio sobre las representaciones del Maíka en el contexto cultural Rapanui. (Tesis inédita de titulación en antropología). Universidad Academia de Humanismo Cristiano, Santiago.

Roussel, H. (1908). Vocabulaire de la langue de l'île-de Pâques ou Rapanui. Nouvelle Série IX. Lovaina: Le Muséon.

Routledge, K. (1919). The mystery of Easter Island: The story of an expedition. Londres: Sifton, Praed \& Co Ltd.

Sadler, M., Fajreldin V., Cortés, M., Montecino, S., Salazar, G., Carrasco, A. M. \& Obach, A. (Coord.) (2006). Los dominios de la salud y la cultura: Estudio de caracterización de los factores de riesgo y vulnerabilidad frente al VIH/SIDA en pueblos originarios. Santiago: CONASIDA, Ministerio de Salud.

Santa Coloma, M. E. (2001). Transición demográfica y social en Rapa Nui (Isla de Pascua). (Tesis inédita doctoral). Universidad de Barcelona, Barcelona.

Santibañez, H. (1986). Migración pascuense en Viña del Mar. (Tesis inédita de titulación en antropología). Universidad de Chile, Santiago.

Saura, B. (2019). Un poisson nommé Tahiti: Mythes et pouvoir aux temps anciens polynésiens (Tahiti, Rai'atea, Hawaii, NouvelleZélande). Punahuia: Au vent des îles, Maison de Sciences de l'Homme du Pacifique.

Schell, P. A. (2001). Capturing Chile: Santiago's Museo Nacional during the Nineteenth Century. Journal of Latin American Cultural Studies: Travesia, 10(1), 45-65.

Schorch, P., Kahanu, N., Mallon, S., Moreno Pakarati, C., Mulrooney, M., Tonga, N. \& Tengan, T. (2020). Refocusing ethnographic museums through oceanic lenses. Honolulu: University of Hawai'i Press.

Seelenfreund, A. (1980). Ahu Tautira: Secuencia y cambios arquitectónicos de un antiguo centro ceremonial sagrado en Isla de Pascua. (Tesis inédita de licenciatura en arqueología y prehistoria). Santiago: Universidad de Chile, Santiago.

(1988). Ahu Tautira: Architectural changes and cultural sequence of an ancient ceremonial platform on Easter Island. Clava, (4), 69-82.

(2000). Easter Island burial practices. En Stevenson, C. \& Ayres, S. W. (Eds.), Easter Island archaeology: Research on early Rapanui culture (pp. 81-103). Los Osos (California): Easter Island Foundation, Bearsville Press.

(2007). La investigación arqueológica antropológica médica en Rapanui. En Lira, E. (Ed.), Cuestiones éticas y la comunidad: Bioética en investigación en ciencias sociales: 3er taller organizado por el Comité Asesor de Bioética de Fondecyt-CONICYT (diciembre). Santiago: CONICYT.

(2009). Patrimonio arqueológico. En Arancibia, V. (Comp.),
Rapa Nui: iorana te ma'ohi: Dilemas estratégicos (pp. 33-53). Santiago: Universidad Católica de Chile.

Seelenfreund, A. \& Holdaway, S. (2000). Color symbolism in Easter Island burial practices. En Stevenson, C. y Ayres, S. W. (Eds.), Easter Island archaeology: Research on early Rapanui culture (pp. 103-108). Los Osos (California): Easter Island Foundation, Bearsville Press.

Seelenfreund, A. \& Mardones, A. (2018). El doble descubrimiento en Rapa Nui: Una mirada desde los textiles. Antropologías del Sur, 5(10), 17-38.

Shaw, L. (2000a). Human burials in the coastal caves of Easter Island. En Stevenson, C. y Ayres, S. W. (Eds.), Easter island archaeology: Research on early Rapanui culture (pp. 59-80). Los Osos (California): Easter Island Foundation, Bearsville Press.

(2000b). The investigation of an Ahu Poe Poe and two

Avanga on Easter Island. En Stevenson, C. y Ayres, S. W. (Eds.), Easter Island archaeology: Research on early Rapanui culture (pp. 1326). Los Osos (California): Easter Island Foundation, Bearsville Press.

Štambuk, P. (2010). Rongo: la historia oculta de Isla de Pascua. Santiago: Pehuén.

(2016). Iorana \& Goodbye: Una base yanqui en Rapa Nui. Santiago: Pehuén.

Stefan, V. (2001). Origin and evolution of the Rapanui of Easter Island. En Morin, F. J. (Ed.), Pacific 2000: Proceedings of the Fifth International Congress of Easter Island and the Pacific (pp. 133-143). Los Osos: Easter Island Foundation.

Tepano, U. (2015). Los manuscritos de Uka. Rapa Nui: Rapanui Press.

Thomas, N. (1996). Out of time: History and evolution in anthropological discourse. Ann Arbor: The University of Michigan Press.

Thompson, W. (1891). Te Pito te Henua, or Easter Island. Washington: Smithsonian Institute Museum.

Torres, P. (2010). Te kuhane o te kainga: El paisaje y la persona en Rapa Nui. (Tesis inédita de titulación en antropología). Universidad Academia de Humanismo Cristiano, Santiago.

Van Tilburg, J. A. (2003). Among stone giants: The life of Katherine Routledge and her remarkable expedition to Easter Island. Nueva York: Scribner.

Van Tilburg, J. A., Dunn, R. K. \& Sherwood, S. (2020). Rano Raraku statue quarry: Preliminary interpretations of human activities suggested by recent excavations, geological mapping and coring, soils micro-morphological analyses and related scientific tests ( $p p$. 115- 128). En Vogt, B., Kühlem, A., Mieth, A., Bork, H.-R. (Eds.), Easter Island and the Pacific: Cultural and environmental dynamics (pp. 115-128). Santiago: Rapanui Press.

Vargas, P., Cristino, C. \& Izaurieta, R. (2006). 1000 años en Rapa Nui: Arqueología de asentamiento. Santiago: Editorial Universitaria, Instituto de Estudios Isla de Pascua, Universidad de Chile.

Vergara, V. (1939). La Isla de Pascua: Dominación y dominio. Santiago: Academia Chilena de Historia.

Weisner, M. \& Fajreldin, V. (2003). Mi remedio pascuense: Cultura 
médico-política en Rapanui. Revista de la Escuela de Antropología, Universidad Nacional de Rosario, (8), 43-58.

(2005). La sangre de Rapanui: Historia, poder y bioética al nacer del siglo XXI: Aportes para una antropología médica crítica. Revista de la Escuela de Antropología, Universidad Nacional de Rosario, (9), 45-58.
Young, F. (2011). Unwriting "Easter Island" listening to Rapa Nui. (Tesis inédita de doctorado). University of Hawai'i, Manoa.

Zurob, A. C. (2009). Ta'aku poki: Cambio y continuidad en las estrategias de crianza rapanui: Un acercamiento a la transmisión en diferencia. (Tesis inédita de titulación de antropólogo). Universidad de Chile, Santiago. 